\title{
WestVirginiaUniversity
}

THE RESEARCH REPOSITORY @ WVU

Graduate Theses, Dissertations, and Problem Reports

2007

\section{Tattooing and high-risk behavior among adolescents}

Tiffany Lynn Stickel

West Virginia University

Follow this and additional works at: https://researchrepository.wvu.edu/etd

\section{Recommended Citation}

Stickel, Tiffany Lynn, "Tattooing and high-risk behavior among adolescents" (2007). Graduate Theses, Dissertations, and Problem Reports. 763.

https://researchrepository.wvu.edu/etd/763

This Thesis is protected by copyright and/or related rights. It has been brought to you by the The Research Repository @ WVU with permission from the rights-holder(s). You are free to use this Thesis in any way that is permitted by the copyright and related rights legislation that applies to your use. For other uses you must obtain permission from the rights-holder(s) directly, unless additional rights are indicated by a Creative Commons license in the record and/ or on the work itself. This Thesis has been accepted for inclusion in WVU Graduate Theses, Dissertations, and Problem Reports collection by an authorized administrator of The Research Repository @ WVU. For more information, please contact researchrepository@mail.wvu.edu. 


\title{
TATTOOING AND HIGH-RISK BEHAVIOR AMONG ADOLESCENTS \\ By
}

Tiffany Lynn Stickel

\author{
A THESIS \\ Submitted to \\ The College of Human Resources and Education \\ at West Virginia University \\ in partial fulfillment of the requirements \\ for the degree of \\ Master of the Arts \\ in \\ Educational Psychology \\ Department of Technology, Learning, and Culture \\ Morgantown, West Virginia \\ 2007 \\ Committee Chair: Carol Markstrom, Ph.D. \\ Erron Huey, Ph.D. \\ Jeong-Ju Yoo, Ph.D.
}

Keywords: adolescent tattooing, high-risk behavior, tattoo motive

Copyright 2007 Tiffany Lynn Stickel 


\section{ABSTRACT \\ Tattooing and High-risk Behavior among Adolescents}

By

\section{Tiffany Lynn Stickel}

High-risk behavior in the domains of tobacco, alcohol, and drug use, and sexual behavior were investigated in relation to tattoo presence/absence among adolescents aged 18-22 years. Adolescents' motivations to become tattooed were also explored.

Participants included 400 tattooed and non-tattooed (147 male, 253 female) students at West Virginia University. Self-report questionnaires, which included items from the 2005 Youth Risk Behavior Surveillance System (YRBSS) as well as items derived by the investigator, were used to assess risk-taking behavior, tattoo presence/absence, and motives for obtaining/not obtaining tattoos. A significant relationship between high-risk behavior and tattooing was found using crosstabulation and chi-square analyses, and significant associations between tattoo motive and high-risk behaviors were found using independent samples $t$-tests and 2x2 ANOVA analyses $(\alpha=.05)$. Findings confirm previous research on tattooing and high-risk behavior and extend research on motives for tattooing. 


\section{ACKNOWLEDGEMENTS}

I would like to thank all of my committee members for guiding me through this challenging, yet worthwhile, experience they call a master's thesis. Your unique contributions helped me to develop my thesis into something I am proud of. Dr. Markstrom, I would like to thank you for reminding me to take everything one step at a time, to be thorough in my research, and for introducing me to the world of academia. Dr. Huey, thank you for always encouraging me to see the big picture, and for helping me to be a critical researcher and thinker. Dr. Yoo, your research interests inspired my own, and I thank you for involving me in projects that challenged and prepared me for my own investigations. I have learned so much from all of you, and I cannot thank you enough for all of the knowledge and experience I have gained in working with you.

Also, I would like to extend a special thanks to Kathie... I could not have done it without your invaluable advice! And last, but certainly not least, Ross, I thank you so much for your support and encouragement every step of the way. 


\section{Table of Contents}

Abstract $\quad$ ii

Acknowledgements

Table of Contents iv

List of Tables vi vi vivis

List of Figures vi

Chapter I

Introduction $\quad 1$

Problem Statement 2

Purpose 3

Chapter II

Review of Literature $\quad 4$

Overview 4

Symbolic Interaction Theory 4

Appearance Management and Perception 9

$\begin{array}{ll}\text { Subculture Identity Theory } & 14\end{array}$

Cross-Cultural Body Modification $\quad 16$

Tattooing in the United States 17

High-Risk Behavior 21

High-Risk Behavior and Tattoos $\quad 26$

Research Findings on Tattooing and High- 28

Risk Behavior

Research Findings on Tattooing, Motivation 34 and High-Risk Behavior

Summary of the Review of Literature 35

Hypotheses 36

Chapter III

$\begin{array}{ll}\text { Methods } & 37\end{array}$

Pilot Study $\quad 37$

Design $\quad 37$

Sample $\quad 37$

Recruitment of the Sample $\quad 37$

Procedure $\quad 38$

Results $\quad 39$

Primary Study $\quad 43$

Design $\quad 43$

Sample $\quad 46$

Recruitment of the Sample $\quad 46$

Instrumentation $\quad 47$

Motives for Obtaining Tattoos 48

High-Risk Behavior $\quad 48$

Procedure $\quad 49$ 
Chapter IV

Results

Chapter V

$\begin{array}{ll}\text { Discussion } & 63\end{array}$

Interpretation of the Results $\quad 63$

$\begin{array}{ll}\text { Limitations of the Study } & 71\end{array}$

$\begin{array}{ll}\text { Future Research } & 72\end{array}$

$\begin{array}{ll}\text { Conclusion } & 73\end{array}$

$\begin{array}{ll}\text { References } & 75\end{array}$

$\begin{array}{ll}\text { Appendices } & 81\end{array}$

Appendix A: Pilot Questionnaire $\quad 83$

Appendix B: Pilot Study Cover Letter to $\quad 87$

Participants

Appendix C: Pilot Questionnaire Results: Items 5

and 8-10

Appendix D: Research Questionnaire 92

Appendix E: Research Study Cover Letter to 98

Participants

Curriculum Vitae

99 


\section{List of Tables and Figures}

Tables

Table 1. Applicable Assumptions of Symbolic Interaction and Appearance Management and Perception Theories

Table 2. Prevalence of Selected High-risk Behaviors among High-school Students

Table 3. Intrinsic/symbolic and Extrinsic/social

Motives

Table 4. Sample Characteristics by Tattooed, Non

Tattooed, and Total Participants

Table 5. Tattooed and Non-Tattooed Participants'

Engagement in Significant High-Risk

Behaviors

Table 6. Analysis of Variance for Total Risk Level

Table 7. Male and Female Participants' Engagement

in Significant High-Risk Behaviors

Table 8. Correlation Matrix produced by Factor

Analysis on the Total Tattooed Sample

Table 9. Factor Loadings, Communalities, and

Percent Variance for Factors 1, 2, and 3

Table 10. Significant Results of $t$-test for Factors with

Risk-Behavior Items as Grouping Variables

Table 11. Simple Regression Analyses between

Factor Scores and Total Risk Level

Table 12. Significant Results of $t$-test for Motives

with Risk-Behavior Items as Grouping Variables

Table 13. Simple Regression Analyses between Motives and Total Risk Level

Table C1. Pilot Item 5 Responses and Corresponding Research Questionnaire Items

Table C2. Pilot Items 8-10 Responses and

Corresponding Research Questionnaire Items

Figures

Figure 1. Delineation of variables for each hypothesis. 


\section{CHAPTER 1}

\section{INTRODUCTION}

The ancient practice of tattooing has existed for thousands of years and has been widely used among many cultures, but has only recently moved into mainstream Western culture (Irwin, 2001; Sanders, 1988). This apparent delay is partially due to differences in cultural significance. Tattoos are symbols that communicate different meanings that vary cross-culturally. In some societies, tattoos are an integral part of the cultural belief system, and in others, they are symbols of societal outcasts. In the United States, the tattoo was formerly a mark associated with deviants and those of the lower social classes, but can now be observed among members of all social statuses (Irwin; Sanders, 1991/1999).

Not only are tattooees ${ }^{1}$ becoming a more socially diverse group, they are becoming a younger group as well. The adolescent tattooing trend was likely initiated by the media, and has quickly gained popularity among adolescents and their peer groups (Armstrong, Roberts, Owen, \& Koch, 2004; Irwin, 2001). As tattoos moved into the mainstream, they became visible in media advertisements and on the bodies of athletes and celebrities. Adolescents are regularly exposed to media messages, so it was inevitable that they would begin to engage in tattooing as well.

The adoption of tattooing by adolescents raises concern among researchers for several reasons. It has been proposed that adolescents are prone to making immature judgments and hasty decisions (Steinberg, 2003). Subsequently, they may not fully consider the physical, psychological, and social risks associated with tattooing. First, the process of tattooing, which involves the use of needles to pierce the skin, places

\footnotetext{
${ }^{1}$ The term "tattooees" refers to those individuals who have obtained a tattoo.
} 
one at risk for contracting blood-borne diseases and infections. Second, tattoos are semi-permanent markings that are difficult to remove. This poses a problem if an individual later feels ashamed of a tattoo, which can lead to negative psychological consequences such as low self-esteem (Armstrong \& Pace Murphy, 1999; Houghton, Durkin, Parry, Turbett, \& Odgers, 1996). Third, societal consequences must also be mentioned. Although tattoos are more widely accepted than they were several decades ago, they often carry a stigma in certain contexts in which tattooees may experience differential treatment (Irwin, 2001).

Because tattooing is sometimes considered a high-risk behavior, it has been studied in relation to other high-risk behaviors among adolescents. In this study, the relationship between adolescent tattooing and risk-taking behaviors, as well as the role of motive in this relationship, was examined.

\section{Problem Statement}

Much of the research on adolescent tattooing has been conducted in order to aid healthcare providers in the identification of high-risk and problem behaviors among this age group. According to this research, if adolescent tattooing is related to high-risk behavior engagement, then healthcare professionals can use tattoos as tangible indicators that their patients may be engaging in other high-risk behaviors as well.

While research supports the correlation between tattooing and high-risk behavior among adolescents (Brooks, Woods, Knight, \& Shrier, 2003; Carroll, Riffenburgh, Roberts, \& Myhre, 2002; Deschesnes, Finès, \& Demers, 2006; Roberts \& Ryan, 2002), it fails to examine adolescent tattooees as the diverse, heterogeneous 
group that they are. Researchers have emphasized that not all adolescent tattooees engage in high-risk behavior, but few have considered the possible reasons for the behavioral differences among members of this group.

Purpose

The current research builds upon existing research to examine adolescents' motives for becoming, and not becoming, tattooed. Some researchers have proposed the notion of a dichotomy among motives to become tattooed, suggesting that some could represent intrinsic/symbolic reasons, while others could reflect extrinsic/social reasons. The nature of the motive, then, may be indicative of the factors that contribute to engagement in risk-taking behavior.

The present study sought to determine whether various motives served as moderating variables in the relationship between tattooing and high-risk behavior among adolescents. Adolescent tattooees, like adolescent risk-takers, are a heterogeneous group whose members must be examined more carefully. Researchers must examine motive as one of several possible factors that makes tattooed individuals different from one another. The nature of an adolescent's motive for becoming tattooed may be indicative of other behaviors, both constructive and destructive, in which the adolescent engages. Thus, the examination of motive in the current study could aid researchers in determining why some adolescent tattooees are high risk-takers, and others are not. 


\section{CHAPTER 2}

\section{REVIEW OF THE LITERATURE}

\section{Overview}

Symbolic interaction and appearance management and perception theories are discussed as relevant theoretical background to the study of adolescent tattooing and high-risk behavior. The practice of tattooing cross-culturally and in the United States is discussed, with particular emphasis on the symbolism of tattoos in Western culture. Research findings on high-risk behavior among adolescents are presented, and literature concerning the relationship between adolescent tattooing and high-risk behavior is examined. The current research study was conducted in light of the deficiencies of recent research on tattooing and high-risk behavior. Research hypotheses derived from this review of literature as well as from pilot data on adolescent tattooing follow.

\section{Symbolic Interaction Theory}

Many of the concepts that would later be essential to symbolic interaction theory were proposed in the works of George Herbert Mead. At the heart of symbolic interaction, as well as human interaction, are symbols, which allow individuals to refer to objects, events, concepts, and motives that are not immediately present (Mead, 1934/1964). For this reason, Mead believed that symbolic thinking is a uniquely human trait that bridges the gap between individuals and the situations in which they interact. Thus, symbols are constructed by humans for use in social situations. In concurrence with this notion, Stone and Farberman (1970a) asserted that "Symbols are nothing without man. Man is nothing without symbols" (p. 148). For the 
purposes of the present study, it is useful to examine four propositions of symbolic interaction theory as found in Manis and Meltzer (1978a). The assumptions of symbolic interaction and appearance management and perception theories as they apply to the present study are also shown in Table 1.

\section{Table 1}

Applicable Assumptions of Symbolic Interaction and Appearance Management and Perception Theories

\begin{tabular}{|l|l|}
\hline Theory & Assumption \\
\hline Symbolic Interaction & 1. Distinctively human behavior and interaction are \\
carried through the medium of symbols and their \\
meanings. \\
2. Human beings are active in shaping their own \\
behavior. \\
3. Human beings construct their behavior in the course \\
of its execution. \\
4. An understanding of human conduct requires study of \\
the actors' covert behavior. \\
1. Humans create their own realities, in part, by \\
managing their appearances. \\
2. To fit their lines of action together, people use \\
symbols. \\
3. We act toward other people, in part, on the basis of the \\
meanings their appearances hold for us. \\
4. Meanings associated with appearance symbols emerge \\
from social interactions with others. \\
5. Meanings assigned to clothing and appearance are \\
manipulated and modified through interpretive \\
processes.
\end{tabular}

Note. The symbolic interaction assumptions are from Symbolic Interaction (pp. 6-9), by J.G. Manis and B.N. Meltzer (Eds.), 1978a, Boston: Allyn \& Bacon. The appearance management and perception assumptions are from The Social Psychology of Clothing (2 ${ }^{\text {nd }}$ ed.) (pp. 41-44), by S.B. Kaiser (Ed.), 1997, New York: Fairchild.

First and foremost, it is proposed in symbolic interaction theory that symbols and their meanings are the vehicles by which human relations occur (Manis \& Meltzer, 1978a). Symbols used in social situations may include spoken words, gestures, clothing, or in the case of the present study, tattoos. According to symbolic 
interactionists, individuals ascribe meaning to such symbols and use them in everyday interaction with others and during reflection with oneself (Faules \& Alexander, 1978; Manis \& Meltzer). Because meanings are socially constructed, individuals build their own realities within their social groups based on the symbols that are important to them. Researchers, then, must understand the symbols important to a group of interest in order to fully understand the actions of its members (Blumer, 1970). Thus, one cannot study adolescent tattooees without first understanding the adolescents themselves, the personal meaning of their tattoos, and the motives behind their actions.

An individual's actions are subject to interpretation by others, and the meanings of such symbols are not always agreed upon by all parties (Blumer, 1970). In day to day communication, there is a constant need for individuals to define the message they want to convey to others, as well as to interpret others' actions. It is this cycle of "definition and interpretation" (p. 286) that makes symbolic interaction an unending process that is present in all communicative situations, from those of friendly discourse to conflicts between adversaries (Blumer). The goal of interaction, then, is to create significant symbols, or meanings that are agreed upon by all parties involved (Mead, 1959/1964; Stryker, 1978).

Symbols do not only refer to present situations. Rather, they allow one to build knowledge of something from past personal experiences as well as the experiences of others (Faules \& Alexander, 1978; Mead, 1934/1964). Symbols may also serve as indicators of action. Thus, by observing another's intonation, gestures, and other communicative symbols, one is able to anticipate what may happen in the 
near future (Stryker, 1978). The notion that symbols are indicative of present and future action is particularly salient to the study of adolescent tattooees. A stranger may observe a tattoo on the body of an adolescent and try to predict the adolescent's behavior based on that observation. In the same way that colored clothing symbolizes gang affiliation, tattoos are also used to symbolize many different things (Armstrong et al., 2004). The present study sought to determine whether or not adolescents' tattoos were symbols indicative of a high-risk lifestyle.

It is also stated in the second proposition of symbolic interaction theory that humans are not passive creatures; instead, they play active roles in directing their own behavior and in responding to the behavior of others (Manis \& Meltzer, 1978a; Mead, 1934/1964; Stone \& Farberman, 1970b). Because symbols, and subsequently actions, are socially constructed, no one person is obligated to follow an unchanging path throughout life. Rather, individuals may reevaluate personal symbols at any time, ascribe new meaning to them, and change their course of action as they wish (Blumer, 1970). Even deviance is a socially constructed notion. Those who engage in deviant behavior define which actions will be considered deviant (Manis \& Meltzer, 1978b). This proposition is an important one in regards to the present study. If human beings are active in shaping their own behavior, such as getting a tattoo, then tattooing is a choice. Researchers must inquire as to why adolescents choose this particular behavior.

According to the third proposition of symbolic interaction theory, individuals actively construct their actions and behaviors as they go along. That is to say, events in the very recent past may shape a person's future behavior (Manis \& Meltzer, 
1978a). Day to day interaction is an ongoing process that requires one to constantly reevaluate his or her actions, goals, values, and behavior, as well as the behavior of others. Situations, meanings, and symbols are ever-changing, so an individual's behavior cannot always be preconceived (Blumer, 1970).

Becker (1978) believed that deviant behavior is learned through such a process. Persons surrounded by a deviant environment come to learn about and accept the actions of others, and eventually partake in the behaviors themselves. Perhaps this is also true of adolescent tattooees. Adolescents may learn to engage in high-risk behaviors from social peers who are engaging in a high-risk lifestyle themselves. In her research among middle-class tattooees, Irwin (2001) found that many individuals were inspired to become tattooed after being involved in deviant groups with peers. It may be, then, that expression through tattooing becomes part of a high-risk lifestyle for adolescents.

It has been established that interaction is largely based on symbols and the meanings ascribed to them. Further, development of symbols and construction of behavior are accomplished by each person on a personal, individual level. To understand the behavior of individuals, then, it is necessary to understand their covert behavior and see the world from their perspective (Blumer, 1970; Manis \& Meltzer, 1978a). In this fourth assumption of symbolic interaction theory, the need to examine individuals' motives, or outward justifications for their actions, is emphasized (Faules \& Alexander, 1978). Faules and Alexander also contended that a particular motive is not the cause of a behavior; nevertheless, it is helpful in determining an individual's attitude toward their own behavior. 
Researchers are able to gather information regarding an individual's covert behavior through a careful study of his or her overt behavior (Meltzer, Petras, \& Reynolds, 1978). A widely used tool in research today is the self-report questionnaire, which asks research participants to comment on their own actions, attitudes, and motives. This method does not give an exact depiction of a person's internal world, but does provide important insight into his or her self-reported behavior. Faules and Alexander (1978) stated that "motivated acts are characterized by choice, control, and an agenda" (p. 144). If the acquisition of a tattoo by an adolescent is a motivated act, then it requires further research to better understand the behavior as well as its correlates. The present study sought to gain an understanding of adolescent tattooing and its relationship with high-risk behaviors via exploration of adolescents' motives to become tattooed.

\section{Appearance Management and Perception}

Appearance management and perception, a concept included in the social psychology of appearance approach, complements symbolic interaction theory. It is stressed in symbolic interaction theory that communication includes a dual process of presentation and interpretation. Appearance management and perception utilizes both processes, outlined by the following five assumptions (see Table 1), to explain the presentation and interpretation of symbols that comprise one's appearance (Kaiser, 1997). An individual's appearance is undoubtedly an important symbol, as it is among the most observable of human qualities (Johnson \& Lennon, 1999).

The first assumption of appearance management and perception states that individuals control and create their own appearances, thus playing an active role in 
constructing their personal realities (Kaiser, 1997). Once again, adolescents' active role in appearance management is key; some adolescents choose to become tattooed, and the present study examined their motives for doing so. In accordance with the first assumption of symbolic interaction theory, many elements of a person's appearance carry deliberate or unintentional meaning (Manis \& Meltzer, 1978a). These appearance-related symbols have been the focus of current research; some believe that one's outward look is a visible representation of covert personal aspects (O'Neal, 1999). From a medical standpoint, Roberts and Ryan (2002) asserted that understanding the appearance management behavior of adolescents may allow healthcare providers to better manage any behavioral problems reflected by their appearance.

According to Mead (1970), everyone has a need to present themselves outwardly, whether it is to one person or to the entire world. A common concept among symbolic interaction theory and appearance management and perception is that of self presentation to others. The importance of this concept lies in the exchange of information made possible when one presents him or herself to others. In a social situation, individuals attempt to gather information about one another (Goffman, 1978), and this is first accomplished by observing one's appearance. Because appearance can be personally controlled, an individual has the power to reveal aspects of his or her appearance as he or she sees fit. The tattoo is a highly controllable symbol that is used to convey meaning at the wearer's discretion. When obtaining a tattoo, one chooses the location of the mark, determining when and by whom the tattoo can be seen (Armstrong et al., 2004). 
It is proposed in the second assumption of appearance management and perception that humans use symbols in order to maintain continuity among "lines of action" (Kaiser, 1997, p. 42). According to Kaiser, lines of action simply refer to behaviors and actions carried out by the individual. As humans maintain relationships with a number of different people (Mead, 1970), and because situations and environments are in constant flux, it is helpful when one is able to maintain some structure across all contexts. Symbols provide individuals with a method for maintaining this structure (Kaiser). If symbols are the substance of human interaction, as posited by symbolic interaction theory (Manis \& Meltzer, 1978a), then adolescents can use tattoos as fairly permanent symbols that represent them across many interaction situations, contexts, and roles.

Sanders (1991/1999) pointed out that some aspects of appearance are transient, and easily changed, while others are more permanent, and thus "carry more weighty symbolic baggage" (p. 141). Tattoos among adolescents are of particular interest in the present study because of this observation. In the process of outwardly presenting themselves, one may ask why adolescents choose to use such a permanent mark. Houghton et al. (1996) found that many individuals who acquired a tattoo during their adolescence regretted it later in life. While adolescents' need for experimentation may lead them to obtain tattoos, Houghton et al. stressed that this experimentation often results in a mark that is rather permanent. Some adolescents may not fully understand tattoos as permanent body modifications that have various consequences years later. This phenomenon also applies to reckless behavior; adolescents may be more likely to engage in other impulsive, high-risk behaviors because they do not 
understand that their actions may have negative repercussions (Arnett, 1995). The current study sought to determine whether or not adolescent tattooing and high-risk behavior were associated. In an attempt to maintain continuity across lines of action, perhaps adolescents engaging in deviant behavior also seek to represent themselves via deviant symbols (i.e., tattoos).

The interpretation aspect of the presentation/interpretation duality of symbolic interaction is evident in the third assumption of appearance management and perception. According to this premise, one's actions toward others are partially based upon his or her interpretation of the appearance of others (Kaiser, 1997). That is to say, symbols mean various things to different people, and humans tend to act according to what they perceive (Blumer, 1970; Stone, 1970). Interpretation is a highly influential factor in the study of deviance. For Erikson (1970), deviance is not created by the individual, but by society, which ultimately determines whether or not an act is deviant. Thus, others' reactions to and interpretations of behavior define an individual's deviance. Tattooees, in general, are often seen as deviants by society; their permanent body alterations often mean negative things to outsiders (Irwin, 2001). The present study sought to determine whether or not this assumption was supported by current research among the adolescent population.

The fourth assumption of appearance management and perception asserts that meanings of symbols are different for everyone; it is important to note that these meanings are socially constructed and are derived through interaction (Kaiser, 1997). Faules and Alexander (1978) asserted that one's reaction to symbols is a learned behavior, and is based on his or her own previous experiences. Thus, people react to 
others and their appearances based upon the way others before them have acted (Blumer, 1970). As they observe the reactions and interpretations of others, individuals learn how others respond to particular symbols, and may adjust their own personal appearance accordingly.

The media plays an essential role in the social construction of symbolic meaning and appearance management. As DeMello (1995) observed, tattooing magazines have done a great deal in the past several decades to create a more socially acceptable meaning for tattoos among middle-class citizens. Adolescents receive messages regarding tattoos from a number of different sources, and decide whether or not to obtain them based upon their culturally constructed interpretation of body modification. It is also important to note that adolescents do not always choose to obtain tattoos when their surrounding social groups encourage this behavior; adolescents may also obtain tattoos because they have observed nothing but social disapproval for them (Irwin, 2001).

The symbolic meaning of appearance is clearly subject to interpretation. The fifth assumption of appearance management and perception takes this notion a step further by stating that symbolic meanings can be controlled, changed, and negotiated (Kaiser, 1997). The ability to control symbolic meaning places a great deal of power in the hands of individuals. Essentially, humans are capable of expressing whatever is in their interest to express at the particular time. Through symbolic interaction, humans often have the means to control the situations in which they interact. By observing how symbols are interpreted by others, individuals may alter their 
appearance in order to gain a desired reaction or to influence a social situation (O'Neal, 1999).

As with other appearance-related items, individuals with tattoos have the power to control the information conveyed by the tattoo as well as when and where their tattoos will be seen (Armstrong et al., 2004; Johnson \& Lennon, 1999). Because they use such a noticeable, self-controlled method of expression, one may ask what adolescent tattooees are trying to convey through body modification. Tattoos, like other symbols, are subject to interpretation and likely hold many different meanings for the adolescents who obtain them.

Symbolic interaction theory and the social psychology of appearance explain humans' use of symbols to convey messages in social interaction. These theories also provide insight into the way adolescents might use tattoos as forms of expression. The present study also examined the relationship between high-risk behavior and adolescent tattooing. Because high-risk behavior and tattooing are potentially parts of a collective lifestyle, subculture identity theory serves as a supplement to symbolic interaction theory and the social psychology of appearance in examining adolescent behavior.

\section{Subculture Identity Theory}

Youth subcultures are thought to emerge out of adolescents' need to establish themselves as a group in a world where they have little social power and recognition (Szostak-Pierce, 1999). According to Szostak-Pierce, subcultural youth are best identified by their distinct style. Assuming that adolescents form a disadvantaged group, they turn their feelings of powerlessness into a creative display of style. This 
style may include listening to particular genres of music, engaging in certain types of behavior, and most apparently, managing their appearance in distinct ways (Polhemus, 1994/1999; Szostak-Pierce).

In their observation of the "body art subculture" (p. 280) among college students, Armstrong et al. (2004) observed that group members maintain a unique, intricate social existence. Students with body modifications such as tattoos and body piercings perceived themselves to be part of a separate group with specific goals. The tattoos and body piercings of members discouraged certain individuals from entering the group, while attracting others. Thus, group membership was largely regulated by the appearance of the participants.

A common concept among subcultures is that of group conformity, which arises from those who blindly adhere to group policy as well as those who genuinely share the same goals of the group (Faules \& Alexander, 1978). Faules and Alexander contended that group conformity serves to fulfill individuals' needs. According to this viewpoint, individuals will continue to act according to the group's expectations as long as the group survives to guide members and fulfill their needs.

Polhemus (1994/1999) built on the notion of group conformity and focused on subcultural groups called "styletribes," (p. 451) which are a product of humans' innate need to feel group belonging and purpose. Again, members of this subculture distinguish themselves by engaging in distinctive behavior and presenting themselves in unique ways. Polhemus believed that adolescents, in particular, are drawn to this subcultural lifestyle, especially since they are experiencing a vulnerable transition period. Polhemus also noted that styletribe members often adorn themselves with 
body modifications, such as tattoos, to establish a permanent, unchanging look that makes them distinct from mainstream society.

Based on the implications of subcultural identity theory, perhaps adolescent tattooees who are also risk-takers engage in both behaviors as encouraged by an overall subcultural lifestyle.

\section{Cross-Cultural Body Modification}

Body modification is not a new concept, and has occurred across many cultures for thousands of years, and continues today. Modifications to the body expand far beyond the tattoos examined in the present study to include body-building, use of cosmetics, clothing, hair styling, piercing, scaring, branding, and cosmetic surgery (Sanders, 1989, 1991/1999). According to Sanders (1989), "Body alteration is culture; it is meaningful to the members of the society in which it occurs, and it is produced within complex webs of collective action" (p. 21).

Tattoos are communicative symbols that have various meanings crossculturally. The status of tattoos in society, then, is dependent upon the message they communicate within each culture (Sanders, 1991/1999). The exact time and location of the origin of tattooing is unclear. Rubin (1988a) proposed that tattooing, along with other forms of body modification, was developed by several cultures around the world at different times. According to this theory, civilizations discovered and began using body modification independently of one another from about the $16^{\text {th }}$ century BC to the $1^{\text {st }}$ century AD. Once discovered by several cultures, the practice was passed on to neighboring civilizations or travelers that came in contact with tattooing practices in these groups. 
Past and present accounts of tattooing support the widespread use of the practice. Tattooing has been employed by various groups worldwide, including the ancient Egyptians, Japanese, American Indians, Yoruba of Nigeria and Benin, and the Newar of Nepal. Although tattooing was, and still is, prevalent across many cultures, the purposes served by this practice are diverse. To some, like the ancient Egyptians and Yoruba people, tattoos have had aesthetic value (Bianchi, 1988; Drewal, 1988). For others, tattoos serve to identify individuals by social status, as in the American Indian and Newar cultures (Gritton, 1988; Teilhet-Fisk, 1988). For others yet, tattoos connote deviance, as they do in mainstream Japan (McCallum, 1988; Sanders, 1989).

According to Sanders (1988), tattooing is the oldest and most commonly used form of body modification. Because the practice of tattooing is widespread historically and presently, one must ask whether body modification is indicative of a universal human necessity for personal adornment, rather than a deviant behavior.

\section{Tattooing in the United States}

The function and perception of tattoos has fluctuated throughout American history (Irwin, 2001). Increased travel and growing attentiveness to non-European cultures facilitated the practice of tattooing in the United States in the late 18th and early 19th centuries among sailors and other world-travelers (Rubin, 1988a).

Partially inspired by the discovery of tattooing among ancient Egyptian females, this practice became briefly popular among upper-class women in the early $20^{\text {th }}$ century. American women commonly obtained ornamental tattoos as well as permanent makeup applied by tattoo artists (Sanders, 1991/1999). Since the appearance of foreigncrafted tattoos on American seamen and the invention of the electric tattoo machine 
in the late $19^{\text {th }}$ century, tattooing in the United States was largely associated with social deviants, such as the stereotypical biker or prisoner. In the past decade, however, this form of body modification has become a fairly common symbol among mainstream society (Atkinson, 2003; Grumet, 1983; Irwin; Roberts \& Ryan, 2002). Greif, Hewitt, and Armstrong (1999) asserted that about 7 to 10 million adults in the United States have tattoos.

A tattoo "renaissance" (Rubin, 1988b, p. 233) began in the mid 1900's as tattoos began to emerge among members of the middle class, as well as individuals from various cultural backgrounds. Japanese-inspired tattoos introduced new techniques and colors to the changing industry. Tattooing was no longer an activity of fringe groups; rather, it began to develop a more diverse clientele. Several researchers believed that the media played an instrumental role in the movement of tattooing into mainstream society. In the past decade, tattoos have become visible in television commercials, magazine advertisements, and on countless celebrities and professional athletes (Armstrong et al., 2004; Atkinson, 2003; Irwin, 2001; Rubin). According to DeMello (1995), the modern tattoo renaissance occurred when the media began to define tattooing as a positive, legitimate symbol of expression. The media ignored that tattooing still occurred within deviant groups, and focused its efforts on making this type of body modification attractive to middle-class citizens, as well as youth. Atkinson also believed that the media deliberately advertises tattoos to young people by way of alcohol advertisements, television programs, and the like. Whatever the influence, tattooing has become increasingly popular among the adolescent population (Atkinson; Roberts \& Ryan, 2002). In recent research studies 
regarding body modification, tattooees comprised $7.9 \%-22.2 \%$ of the adolescent samples studied (Carroll et al., 2002; Deschesnes et al., 2006; Drews, Allison, \& Probst, 2000; Houghton et al., 1996; Koch, Roberts, Armstrong, \& Owen, 2005). Deschesnes et al. not only recognized the emerging popularity of tattooing among adolescents, but also felt that it is gaining broader acceptance in society.

Tattoos symbolize something different for everyone, but the greatest difference in representation in Western society occurs between individuals with tattoos and those without. Atkinson (2003) asserted that tattoos signify a form of nonverbal communication by the individuals who obtain them. For instance, individuals often use tattoos as expressions of freedom, personal independence, and uniqueness amid a larger society that is characterized by firm cultural standards and belief systems (Armstrong et al., 2004; Atkinson; Irwin, 2001). Tattoos may represent belonging for wearers as well; they are physical marks that confirm one's connection to social groups such as gangs, fraternities, or religious groups (Armstrong et al.; Irwin; Polhemus, 1994/1999). According to Polhemus, this sense of belonging is especially important to adolescents, who are in a confusing transition period between childhood and adulthood. Tattoos may even be an outlet for adolescents to express the frustrations and pressures characteristic of this life stage (Atkinson; Deschesnes et al., 2006).

For some individuals, tattoos mark a significant life event or the transition from one life stage to another (Armstrong et al., 2004; Irwin, 2001). For others, tattoos demonstrate the personal control and power that an individual has over his/her own body; such meaning is often described by women who have experienced 
controlling relationships in the past (Irwin). While many individuals ascribe complex meaning to their tattoos, some become involved in body modification simply because it is deviant or unconventional by societal standards (Atkinson, 2003).

A non-tattooed individual, however, may react to tattooed people in a variety of ways (Armstrong et al., 2004). There are more recorded accounts of individuals' attitudes about tattoos from those that actually have tattoos, in comparison to those who do not. Armstrong and Pace Murphy (1999) obtained non-tattooed adolescents' opinions regarding tattoos. Many of these adolescents saw tattoos as health risks. In her study of middle class tattooing, Irwin (2001) interviewed the parents of several tattooees and found that tattoos conveyed messages of poor hygiene, dirtiness, and potential disease to them. On a social level, parents felt that their children's tattoos represented deviance and low social status, and reflected negatively on the parents themselves. Similarly, Armstrong and Pace Murphy found that to some parents, tattoos symbolize deviance.

Research has shown that males and females obtain tattoos in relatively equal numbers (Drews et al., 2000; Sanders, 1991/1999). Atkinson (2003) and Miller (1999) believed that tattooing did not always follow this pattern, and that its prevalence among females only recently increased in popularity. While males and females are equally likely to become tattooed, the placement of the tattoo as well as the image it depicts often differs according to gender (Sanders). Drews et al. and Sanders observed that many females placed tattoos in locations that were easily covered with clothing, such as the back or hip; in contrast, males often chose tattoos in more conspicuous areas, such as the arm or shoulder. Sanders attributed this 
occurrence to differing definitions of tattoos as symbols. While males tend to use tattoos as public representations of themselves, females' tattoos serve a more decorative purpose and are kept more private. Further, Sanders observed a difference in the content of the tattoos obtained by males and females; males frequently selected tattoos that were whimsical or aggressive and females often chose floral designs.

It has been emphasized that the symbolism of tattoos greatly varies. To many individuals, tattoos represent deviance, a perception that is reflected in research involving the study of deviant behaviors among tattooed individuals. In particular, researchers have been interested in adolescent tattooees who engage in high-risk behavior.

\section{High-Risk Behavior}

High-risk behaviors can be defined as "a wide variety of behaviors that put adolescents at risk for morbidity and mortality” (Roberts \& Ryan, 2002, p. 1061). While individuals of all ages engage in high-risk behavior, it is quite prevalent in the adolescent years (Arnett, 1996). Included in Table 2 are figures that describe several high-risk behaviors as determined by the 2005 Youth Risk Behavior Surveillance, a nationwide survey that examined the occurrence of high-risk behavior among highschool students (Centers for Disease Control and Prevention [CDC], 2006).

Adolescent high-risk behavior is a very complex phenomenon to which many factors contribute. Genetic and contextual influences, although discussed independently, often act simultaneously and have the largest impact on adolescent risk-taking. Genetic influences on adolescent behavior include factors inherited from the biological parents as well as the biological predispositions characteristic of the life 
stage of adolescence. For example, research has supported the notion that the

tendency for substance use is a behavior that may be passed down from parent to

child (Lerman, Patterson, \& Shields, 2003). It must be emphasized, however, that

heritability only accounts for a small portion of the phenomenon of high-risk behavior

among adolescents.

\section{Table 2}

Prevalence of Selected High-risk Behaviors among High-school Students

\begin{tabular}{|lccc|}
\hline Behavior & \% Males & \% Females & $\begin{array}{c}\text { \% Males and } \\
\text { Females }\end{array}$ \\
\hline Current frequent tobacco use & 9.3 & 9.3 & 9.4 \\
Current heavy drinking & 27.5 & 23.5 & 25.5 \\
Drug use & & & \\
$\quad$ Cocaine & 4.0 & 2.8 & 3.4 \\
$\quad$ Heroine & 3.3 & 1.4 & 2.4 \\
$\quad$ Methamphetamine & 6.3 & 6.0 & 6.2 \\
Ecstasy & 7.2 & 5.3 & 6.3 \\
Inhalants & 11.3 & 13.5 & 12.4 \\
Risky sexual behavior & & & 14.3 \\
$\quad$ Four or more partners & 16.5 & 12.0 & 62.8 \\
Condom use & 70.0 & 55.9 & 23.3 \\
Drug/alcohol use prior to intercourse & 27.6 & 19.0 & \\
\hline
\end{tabular}

Note. Current frequent tobacco use refers to having smoked cigarettes at least 20 days in the past month. Current heavy drinking refers to having five or more drinks in a row within a short period of time in the past month. Drug use refers to having used cocaine on at least one occasion in the past month, and/or having used heroine, methamphetamine, ecstasy, or inhalants at least once in a lifetime. Risky sexual behavior refers to having had sexual intercourse with at least 4 partners in a lifetime, condom usage before the last sexual intercourse, and/or usage of drugs and/or alcohol before the last sexual intercourse. The percentages are based on a sample of 13,953 high-school students. From "Youth risk behavior surveillance - United States, 2005" [Electronic version], by Centers for Disease Control and Prevention, 2006, Morbidity and Mortality Weekly Report, 55, p. 10-22.

While heritable traits may increase an individual's predisposition to engage in certain behaviors, the biological issues common among many adolescents, such as hormonal changes, "sensation-seeking" (Arnett, 1995, p. 67), and changing cognitive abilities, are also important. For instance, Arnett believed that hormone fluctuations in adolescence account for heightened aggressiveness and reckless behavior, especially among males. Further, adolescents may exhibit low impulse control, 
which, when coupled with sensation-seeking, could influence adolescents to make unhealthy decisions that lead to risky behaviors (Arnett; Donohew, Palmgreen, Zimmerman, Harrington, \& Lane, 2003). Sensation-seeking can be described as the "propensity for seeking out novel and intense experiences" (Arnett, p. 67), and may influence individuals' engagement in behaviors that feel exciting or thrilling (Arnett; Steinberg, 2003). Donohew et al. discussed sensation-seeking and impulsivity as personality traits that predispose some individuals to high-risk behavior, while Arnett asserted that sensation seeking is heightened during adolescence for many individuals, and plays a large role in adolescent high-risk behavior.

Cognitive considerations important to the study of adolescent risk-taking include adolescents' sense of “invulnerability" (Lapsley, 2003, p. 25) and judgment (Steinberg, 2003). Adolescents often exude an extreme sense of confidence, and behave as though they are indestructible. According to Lapsley, the context in which adolescents act invulnerable is of particular importance. For example, showing invulnerability in interpersonal situations (i.e., not allowing others' opinions to harm oneself) serves to protect adolescents. On the other hand, invulnerability to danger (i.e., external harmful situations) may lead adolescents to disregard the consequences of high-risk behaviors, such as unprotected sex. Additionally, adolescents' cognitive abilities may limit the maturity in their judgment. Steinberg emphasized that adolescents are not deficient in decision making skills, but in the ability to maturely judge situations due to cognitive, social, and emotional influences.

While there are predispositions that may contribute, in part, to high-risk behavior among adolescents, Arnett (1995) stressed that the context in which an 
adolescent is socialized (i.e., peers, family, and social factors) largely determines whether or not he/she will engage in such behaviors. Steinberg (2003) stated that high-risk behavior among adolescents seldom occurs individually, but happens in group situations. Adolescents' behavior is greatly influenced by their peer group, with whom they spend an increasing amount of time during the teenage years (Warr, 1993). Adolescent peer groups are close-knit entities that require, or at least strongly encourage, conformity of their members (Arnett). According to Deschesnes et al. (2006) and DiClemente, Wingood, and Crosby (2003), adolescents conform to peers' standards and emulate their behavior, even if the cost is engaging in high-risk behavior. Adolescents' exposure to peers who engage in negative behaviors, such as theft or substance use, increases during this life stage, and is a topic of concern among many adults (Warr).

Parental influence also has a role in adolescent risk-taking behavior. For instance, the amount of parental monitoring that occurs in the home may be related to the amount of high-risk behavior in which adolescents engage (Stanton \& Burns, 2003). Parental monitoring, which includes parent-child communication regarding principles and beliefs and parental supervision, seems to have positive effects on adolescent behavior across various age, ethnic, and social groups.

In addition to peer and familial influences, social factors are also related to high-risk behavior in adolescence. According to DiClemente et al. (2003), factors such as media exposure and economic stress affect adolescents' involvement in risktaking behaviors. For instance, various media sources targeted at adolescents, such as magazines, television programs, and advertisements, may romanticize engagement in 
high-risk behaviors, such as tobacco use. While not all adolescents perceive risky behaviors as desirable, those of low socioeconomic status might not have the resources, such as money to purchase condoms, needed to prevent them from engaging in risky behaviors, such as unprotected sex.

For some adolescents, risk-taking and other acts of deviance are learned behaviors that can lead to a way of life (Adler \& Adler, 1978). For instance, many adolescents become lost in the crowd of classmates, peers, and the larger society, and choose to regularly engage in minor high-risk behaviors simply because it is a change of pace, and they can get away with it (Katz, 1988). In a similar way, adolescents might choose to engage in tattooing, which could also be considered a form of highrisk behavior (Armstrong \& Pace Murphy, 1999; Houghton et al., 1996), to symbolize uniqueness and self expression amid that same crowd of classmates, peers and larger society.

The topic of high-risk behavior not only warrants the discussion of influential factors, but also of the co-occurrence of risky behaviors among adolescents. Research has supported the assumption that adolescents who engage in certain risky behaviors are likely to engage in other behaviors of that nature (Biglan \& Cody, 2003). In an effort to explain this trend, Donovan and Jessor (1985) proposed that adolescents' engagement in high-risk behavior is characteristic of a syndrome in which the set of symptoms are risky behaviors and the common factor uniting the symptoms is the notion of "unconventionality" (p. 891). Thus, adolescents engage in various high-risk behaviors that are considered unconventional or deviant, and are more likely to engage in other such behaviors for the same reason. Arnett (1998) 
found similar evidence for a syndrome of high-risk behavior among individuals in late adolescence.

On the other hand, Byrnes (2003) believed that because adolescents do not act in the same manner across all contexts, high-risk behavior engagement is situationspecific, and not characteristic of a syndrome. Thus, adolescents are likely to engage in high-risk behaviors if the situation presents them with the opportunity to do so. Byrnes advocated the development of an integrated approach to the study of high-risk behavior in which both viewpoints (risk-behavior as a syndrome and as situationspecific) are taken into consideration.

\section{High-risk Behavior and Tattoos}

High-risk behavior as a syndrome supports the assumption that adolescent tattooing is related to high-risk behavior. Tattooing may be a desirable act of deviance to adolescents (Atkinson, 2003; Irwin, 2001; Katz, 1988), and could be related to other behaviors characterized by this syndrome, especially if tattooing is considered a high-risk behavior itself. As such, tattooing poses physical and psychological risks to adolescents (Armstrong \& Pace Murphy, 1999; Houghton et al., 1996). While physical risks include contracting Hepatitis or human immunodeficiency virus (HIV), psychological risks include feelings of embarrassment or self-consciousness about a tattoo. Armstrong and Pace Murphy noted that it is particularly unfortunate when adolescents are embarrassed about their tattoos because this age group is very sensitive about appearance. Houghton et al. found that many adults who were tattooed as adolescents were unsatisfied with their tattoos and regretted obtaining them. 
The situation-specific approach to risk-taking might also help support the notion that tattooing is related to high-risk behavior among adolescents. In accordance with this approach, the same genetic and contextual factors that were discussed in relation to risky behaviors may also influence adolescents to become tattooed. For instance, adolescents' predisposition for sensation-seeking may also have a role in the adoption of tattooing as a deviant, high-risk behavior. Adolescent tattooees may experience the process of being tattooed as physically thrilling and exciting. As stated previously, sensation-seeking refers to the search for new experiences that stimulate or arouse the senses (Arnett, 1995). In the same way that driving a car at a high speed might elicit feelings of exhilaration, the sensation of needles pricking the skin during the tattooing process physically arouses some individuals (Arnett, 1996; Deschesnes et al., 2006; Koch et al., 2005). In addition to the physical aspect of being tattooed, the unconventionality associated with having a tattoo may also be thrilling and exciting. For example, some tattooees might find excitement in knowing that they are participating in an act deemed unconventional by society (Atkinson, 2003). Further, Atkinson proposed that tattooing is a more controlled form of high-risk, deviant behavior. Some high-risk behaviors that are stimulating and thrill-producing are harmful to the participant (e.g., binge drinking) and/or those nearby (e.g., reckless driving). In choosing tattooing as a deviant behavior, individuals are able to "walk the tightrope of deviance" (Atkinson, p. 181) and participate in a somewhat safer deviant practice. While some adolescents reap the perceived benefits of tattooing (i.e., experiencing peer group membership or 
feeling the thrill of performing a deviant act), they are still able to conceal their tattoos with clothing, if need be.

Research on adolescent body modification supports the assumption that tattooing is related to high-risk behavior among adolescent males and females (Brooks et al., 2003; Carroll et al., 2002; Deschesnes et al., 2006; Roberts \& Ryan, 2002). The high-risk behaviors commonly studied in relation to tattooing include sexual involvement, substance use, violent behavior, school-related problems, gang affiliation, and suicidal ideation and attempts. The present study focused on current cigarette use, current and lifetime drug use, current and heavy drinking, and sexual risk-taking, as they are behaviors commonly assessed by researchers of tattooing and/or risk-taking, and are salient issues among the college population. Additionally, upon examination of the 1999 version of the instrument used in the present study, researchers observed significantly higher levels of test-retest reliability on items concerning tobacco, alcohol, and drug use and sexual behavior, when comparing them with other items on the questionnaire (Brener et al., 2002).

\section{Research Findings on Tattooing and High-Risk Behavior}

Much of the research conducted on adolescent body modification and highrisk behavior has been approached from a medical standpoint. By identifying body modification as related to other high-risk behaviors among adolescents, researchers proposed that healthcare providers use tattoos, body piercings, and the like as warning signs for possible behavioral problems and/or involvement in risky activities. This proposition is supported by symbolic interaction theory, which indicates that symbols may be indicative of present or future actions (Faules \& Alexander, 1978; Mead, 
1934/1964). Based on previous knowledge and past experiences with tattoos, researchers have found these symbols to be associated with high-risk actions. Thus, upon observation of a tattoo or body piercing on an adolescent patient, physicians are encouraged to discuss the permanency and health risks involved with the body alteration. The physician, as well as teachers, parents, and other figures in the adolescents' lives, are urged to further monitor or counsel the adolescent as appropriate (Armstrong \& Pace Murphy, 1999; Brooks et al., 2003; Carroll et al., 2002; Deschesnes et al., 2006; Roberts \& Ryan, 2002).

In their research on body modification, Brooks et al. (2003) used a questionnaire that addressed body modification (i.e. tattoos, piercing beyond one pair of bilateral earlobe piercings in females, branding, or scarification) and the Problem Oriented Screening Instrument for Teenagers/Alcohol and Drug Abuse Scale (POSIT-ADS) with a sample of adolescent clinic patients aged 14 to 18 years. Body modification was associated with substance use among adolescents. Further, body modification seemed to be a relatively normative risk behavior in this age group (tattooed adolescents comprised $10 \%$ of the sample).

In their study of adolescent body modification (i.e. tattooing and piercing) and high-risk behavior, Carroll et al. (2002) found support for the association between the two variables. These authors observed a distinct difference in adolescent risk-taking behaviors among individuals (aged 12 to 22 years) with tattoos and/or body piercings as compared to those without such body alterations. Although both groups of individuals engaged in high-risk behaviors, those with tattoos and/or body piercings had a higher incidence of, and more consistent involvement in, risky behaviors. The 
authors used a survey based on the 1997 Centers for Disease Control and Prevention Youth Risk Behavior Survey to assess adolescents on a variety of high-risk behaviors, such as disordered eating, violence, gateway drug use (i.e., the use of milder drugs that often leads to the use of harder drugs), hard drug use, sexual behavior, and suicidal ideation. The use of this survey allowed Carroll et al. to not only test for the presence or absence of high-risk behaviors, but to also assess the degree of engagement in these behaviors. Thus, the authors were able to clearly define what constituted a high-risk behavior.

Data from the National Longitudinal Study of Adolescent Health (Add Health) was examined by Roberts and Ryan (2002) with the purpose of identifying the prevalence of tattooing among adolescents and examining this form of body modification as it related to various demographic factors and high-risk behavior. Through Add Health, researchers conducted in-home surveys with adolescents aged 11 to 21 years across the United States. From this data, Roberts and Ryan concluded that tattooing was a common behavior among adolescents, and found support for a relationship between tattooing and high-risk behavior across four dimensions: (a) sexual involvement (including frequent sexual activity and sexual activity at a young age), (b) substance use, (c) violent behavior, and (d) school problems. Thus, tattooed adolescents seemed to be engaging in these behaviors at higher rates than were their non-tattooed peers.

Deschesnes et al. (2006) took the study of body modification and high-risk behavior a step further by characterizing the behaviors that were strongly associated with tattooing and body piercing. High school students 12 to 18 years of age were 
administered a self-report questionnaire which combined questions from the Armstrong Tattoo Survey as well as numerous behavioral measures. Only externalized risk behaviors (e.g., illegal activities, drug use, and gang affiliation) were significantly related to body modification, and internalized problem behaviors (e.g., suicide ideation and psychological distress) were not. The heterogeneity of high-risk takers as a population was made apparent by the finding that only certain types of risk behaviors were associated with body modification.

Armstrong and Pace Murphy (1999) approached the subject of adolescent tattooing somewhat differently than other researchers. In addition to examining tattooing as it related to high-risk behavior, Armstrong and Pace Murphy included other factors related to body modification among adolescents, such as their attitudes toward tattoos, non-tattooed individuals' reactions to body modification, and perceived health risks. The research was conducted via a replication study of tattooing practices and high-risk behavior involving adolescents in grades 7-12. The goal of this research was to obtain information regarding adolescent tattooees. Using information acquired from a self-report survey, Armstrong and Pace Murphy observed several changes in their data, compared to the tattooing practices and highrisk behavior study. For instance, more adolescent females reported having tattoos, adolescents obtained their tattoos at younger ages than previously reported, tattooees were more impulsive in their decisions to become tattooed, and adolescents with tattoos were engaging in more high-risk behaviors than in the model study. Additionally, the non-tattooed adolescents surveyed indicated that they refrained from tattooing mainly to avoid health risks and the regret that may accompany a permanent 
body alteration. Because the practice of tattooing seemed to be gaining momentum in the adolescent population, Armstrong and Pace Murphy recognized the opportunity for health education regarding body modification. Especially in response to nontattooed adolescents' concerns about tattooing, the authors expressed the need to address the permanency of tattoos, healthy decision-making, and the health and psychological risks associated with altering the body.

One of the most common variables studied in relation to tattooing (and other body modifications, such as body piercing, branding, and scarification) is high-risk behavior, including sexual involvement, substance use, violent behavior, schoolrelated problems, gang affiliation, and suicidal ideation and attempts (Armstrong \& Pace Murphy, 1999; Brooks et al., 2003; Carroll et al., 2002; Deschesnes et al., 2006; Roberts \& Ryan, 2002). Other contributing variables to the relationship between tattooing and high-risk behavior that have been studied include demographic and attitudinal factors, as well as characteristics specific to the actual tattoo.

Important demographic factors that must be considered in the study of tattooing and high-risk behavior include sex, age, socioeconomic status (SES), and ethnicity. According to Brooks et al. (2003), males and females appear to be practicing body modification in relatively equal numbers, and at older ages; however, females are more likely than males to actually report body modification. Prior to the modern tattoo renaissance, tattooing was commonly associated with individuals of lower SES (Demello, 1995; Rubin, 1988b; Sanders, 1989). There has been little mention of SES among current research studies, with the exception of Roberts and Ryan (2002), who found tattooing to be significantly more prevalent among 
adolescents from low SES families. In contrast, ethnicity did not seem to play a significant role in tattooing behavior among adolescents (Brooks et al.; Carroll et al., 2002; Roberts \& Ryan).

An effective method for gaining insight into the practice of adolescent tattooing is to examine the attitudes of both individuals with and without tattoos. Adolescents' attitudes about their own tattoos are important, as this life stage is precarious in terms of appearance and self-esteem; feeling regret or shame about a tattoo could have serious psychological consequences (Armstrong \& Pace Murphy, 1999; Grumet, 1983; Houghton et al., 1996). Obtaining the attitudes of non-tattooed adolescents, on the other hand, allows researchers to clearly identify any factors on which tattooees and individuals without tattoos differ (Armstrong \& Pace Murphy).

Factors related to the tattoo itself, such as method of acquirement, location, and motivation, may also have important implications, and have been studied by several researchers. Adolescents may obtain tattoos from either a professional artist or from an amateur. Individuals who accept the risks associated with not being tattooed by a licensed professional (e.g., unsanitary conditions) may frequently engage in other high-risk behaviors as well (Carroll et al., 2002; Houghton et al., 1996). Similarly, the location of an adolescent's tattoo may provide insight into how concerned he or she is with publicly displaying a symbol often perceived to be deviant in society (Phelan \& Hunt, 1998). An adolescent's motivation for obtaining a tattoo, another important factor that may have a unique role in the relationship between tattooing and high-risk behavior, will be discussed in greater detail in the following section (Brooks et al., 2003). 
Much of the research on body modification and high-risk behavior has shown support for an association between the two variables. A major gap exists in the research, however, and was addressed in the present study. Adolescent tattooees are frequently treated as a homogeneous group, but may actually be heterogeneous, with respect to the variety of motivations they represent. The current study addressed the motives of adolescent tattooees in order to determine the role, if any, they have in the relationship between tattooing and high-risk behavior.

\section{Research Findings on Tattooing, Motivation and High-Risk Behavior}

As mentioned earlier, individuals' motives for becoming tattooed have been examined, to some extent, by various researchers. Individuals have cited a number of reasons for becoming tattooed, including the commemoration of special events and achievements, representation of a loved one, need for independence from social constraints, need for emotional management and healing, and desire to express personality traits, individuality, and uniqueness (Armstrong \& Pace Murphy, 1999; Armstrong et al., 2004; Atkinson, 2003; Irwin, 2001; Sanders, 1988).

Brooks et al. (2003) assumed that individual motives and feelings place body modification into one of two categories, "positive self-expression" and "destructive self-mutilation" (p. 48). Similarly, Atkinson (2003) observed a dichotomy among tattoo representations, and categorized them as "marks of disaffiliation" and "marks of conformity" (pp. 164, 186). Marks of disaffiliation represent motivations that highlight one's desire to separate from mainstream conventions or to mark one's separation from familial, relational, or social bonds. On the other hand, marks of conformity represent tattoos that are obtained to commemorate a special event, 
positively manage emotions, or to express individuality. While these distinctions may not accurately describe the attitudes of everyone, it is important to highlight the need for further investigation into the different motives of adolescent tattooees.

Current research has outlined various motives for obtaining tattoos, and some researchers have placed these motives into categories that could represent several purposes. The present study carried this investigation a step further, and examined motive as a possible moderator in the relationship between tattooing and high-risk behavior among adolescents. According to symbolic interaction theory, the study of an individual's covert behavior facilitates the understanding of their observable behavior (Faules \& Alexander, 1978). Consequently, the examination of individuals' covert motives to become and not become tattooed could provide insight into their observable high-risk behaviors.

In order to determine the actual motives individuals have for becoming tattooed, a pilot study was conducted among adolescents with and without tattoos. The results of the pilot study yielded results similar to those in the literature; tattooed individuals seemed to be either extrinsically/socially or intrinsically/symbolically motivated.

\section{Summary of the Review of Literature}

Symbolic interaction and appearance management and perception theories provided a basis for understanding adolescent tattooing and its proposed relation to high-risk behavior. To some adolescents, tattoos are visible symbols that can represent intangible things, such as memories, personality traits, or group membership (Manis \& Meltzer, 1978a; Mead, 1934/1964). Much of the research on 
adolescent tattooees has supported the notion that tattoos are symbols reflective of a high-risk lifestyle.

Research on motives for becoming tattooed maintained the assumptions that individuals actively choose their behaviors as well as use symbols to create their own realities (Kaiser, 1997; Manis \& Meltzer, 1978a). Tattooed adolescents use their body modification to help create an outward appearance that others interpret in various ways. Thus, if adolescent tattooees actively choose to become tattooed, there must also be a reason, or motive, for this choice of behavior. Some researchers have explored motives related to tattooing, and have found evidence for a dichotomy among individuals' reasons for obtaining tattoos. The pilot study discussed previously yielded a similar pattern among motives, and validated the need for further investigation of individuals' reasons for becoming tattooed. In light of these research findings, the following hypotheses were formulated:

Hypothesis 1: There will be no difference in tattoo presence or absence according to SES or biological sex.

Hypothesis 2: Adolescents with tattoos will score at high risk relative to behaviors when compared to adolescents without tattoos.

Hypothesis 3: Tattooed adolescents with extrinsic/social motives for obtaining tattoos will score at high risk relative to behaviors when compared to tattooed adolescents with intrinsic/symbolic motives for obtaining tattoos. 


\section{CHAPTER 3}

\section{METHODS}

\section{Pilot Study}

The following pilot study on adolescent tattooing was conducted in order to develop questionnaire items for a research study on adolescent tattooing and high-risk behavior, which is explained in greater detail in the following section.

Design

The pilot study was qualitative in design, and involved data collection via an open-ended questionnaire. Participants were asked about their motives for obtaining and not obtaining tattoos, and their responses aided the development of a research questionnaire on adolescent tattooing and high-risk behavior. Participant responses to the open-ended questions (items 5 and 8 to 10; see Appendix A) were used to devise multiple-choice questions regarding motive that will be used in the main study.

\section{Sample}

The sample consisted of 133 undergraduate college students (37 males and 96 females). Participants were between 18 and 29 years of age; the mean age was 20 years.

\section{Recruitment of the Sample}

The nonrandom convenience sample for this study was obtained from introductory level Child Development and Family Studies classes, and an introductory level Human Nutrition and Foods class at West Virginia University (WVU). All interested and willing students present in class on the day the 
investigator attended were invited to participate in the study. Overall, most students completed the surveys.

\section{Procedure}

Data needed for the pilot study were collected via an 11-item self-report survey. Data were collected in one session for each introductory level class during the fall 2006 academic semester. Administration of the survey occurred during the regularly allotted class time in the selected classes, and lasted approximately 15 minutes per class.

Prior to distribution of the surveys, students were given information about the study for which their participation was requested. Students were told that the survey was part of a research study being conducted by the investigator in partial fulfillment of the requirements for a master's degree in the department of Technology, Learning, and Culture at WVU. They were informed that data collected in the study would help the investigator develop a questionnaire for a future research study. The investigator announced that students with and without tattoos could participate in the study, but needed to meet the minimum age requirement (18 years of age) for participation. Anonymity and confidentiality were assured, and instructions on completing the survey were given. The investigator told students that surveys would be distributed to everyone in the class, and that they could complete the surveys if they wished.

Students were told that participation in the study was completely voluntary, and that they would not be penalized if they chose not to participate. The investigator made it clear that should students choose to participate, they were not required to answer all of the questions on the survey. They were reminded to not provide any identifying 
information on the materials presented to them, and were informed that the survey would take them approximately 10 minutes to complete. Participants were also asked to read the Institutional Review Board (IRB) approved cover letter, which accompanied the questionnaire (see Appendix B). Students were advised to retain the cover letter, should they need the contact information included in it. Following data collection, each survey was arbitrarily assigned an identification number for data entry purposes.

Results

Following data collection, responses to items 1 to 4,6 , and 7 of the pilot questionnaire were entered into a spreadsheet. From this data, it was tabulated that, of the students sampled, $30(23 \%)$ had tattoos, and $103(77 \%)$ did not have tattoos. Of the tattooed portion of the sample, $7(23 \%)$ were males and $23(77 \%)$ were females; that is to say, $19 \%$ of males and $24 \%$ of females were tattooed.

The raw data obtained from items 5 and 8 to 10 of the pilot questionnaire was analyzed in a qualitative manner. Each non-tattooed individual's response to item 5 of the pilot questionnaire was handwritten by the investigator in the participants' words. Several responses were cited by multiple participants, so a tally of participants who cited each response was recorded. After all data pertaining to item 5 of the questionnaire were compiled, the investigator devised 11 categories under which many of the participants' responses could be represented. Data from items 8 to 10 of the pilot questionnaire were analyzed in a similar manner.

Each tattooed individual's response to item 8 of the pilot questionnaire was handwritten by the investigator in the participants' words. Again, several responses 
were cited by multiple participants, and a tally of participants who cited each response was recorded. Additionally, each respondent's attitude toward his or her own tattoo (as indicated by their responses to items 9 and 10 of the pilot questionnaire) was recorded by the investigator.

After all data pertaining to items 8 to 10 were recorded, the investigator devised 8 categories under which many of the participants' responses could be represented. To further validate the formulation of the motive categories from items 5 and 8 of the pilot questionnaire, the investigator recruited eight raters to devise categories from the given responses. The raters developed motive categories similar to the ones delineated by the investigator. Further explanation of how items 5 and 8 to 10 were used in the development of the research questionnaire follow.

Information obtained from items 5 and 8 to 10 of the pilot questionnaire was important to the development of the research questionnaire that will be used in the primary study (see Appendix C). Participants' responses to item 5 of the pilot questionnaire (which asked, “Are there any particular reasons why you don't have a tattoo?") were used to devise eleven motives, represented in items $6 \mathrm{a}-6 \mathrm{k}$ of the research questionnaire (which asked, "Why did you choose not to become tattooed?;" see Appendix D). Participants were given the opportunity to rank each of the eleven motives included in items $6 \mathrm{a}-6 \mathrm{k}$ on a Likert-type scale (choices were $1-5$, with 1 being "not at all important," and 5 being "very important") in terms of how important each motive was to them in their decision to not become tattooed. An additional item, 61, was also included as an "other" category, which participants could use to cite and rate any other reason for not becoming tattooed. The motives were devised to 
represent the most popular reasons for not becoming tattooed, as cited by the participants. Table $\mathrm{C} 1$ of Appendix $\mathrm{C}$ shows participant responses to item 5 of the pilot questionnaire that were used to develop motives (a to k) for item 6 on the research questionnaire. The first column of the table indicates the item under which each motive (in the second column) is represented. The third column shows the number of respondents that cited each particular reason for not becoming tattooed.

Participants' responses to item 8 of the pilot questionnaire (which stated, "Please list as many reasons that you can think of to explain why you became tattooed.") were used to devise eight motives, represented in items $4 \mathrm{a}-4 \mathrm{~h}$ of the research questionnaire (which asked, "Why did you choose to become tattooed?"). Participants were given the opportunity to rank the personal importance of each of the eight motives to become tattooed (included in items $4 \mathrm{a}-4 \mathrm{~h}$ ) on the same Likert-type scale previously discussed. An additional item, 4i, was also included as an "other" category, which participants could use to cite and rate any other reason for becoming tattooed. The choices were devised to represent the most popular reasons for becoming tattooed, as cited by the participants. Table $\mathrm{C} 2$ shows participant responses to item 8 of the pilot questionnaire that were used to develop choices (a to $h$ ) for item 4 on the research questionnaire. The first column of the table indicates the item under which each motive (in the second column) is represented. The third column shows the number of respondents that cited each particular reason for becoming tattooed. Table C2 also includes information obtained from items 9 and 10 of the pilot questionnaire (which asked "Now that you have a tattoo, has it been a positive or negative experience for you? Why or why not?" and "Do you regret becoming 
tattooed? Why or why not?," respectively). These questions were included to ascertain respondents' attitudes toward their tattoos, and are reflected in the fourth and fifth columns of the table. The fourth column includes the number of participants who cited positive or negative attitudes associated with each response. The fifth column includes the number of participants who regretted and did not regret becoming tattooed, as associated with each response. It should be noted that the choices were not mutually exclusive, and that participants sometimes reflected positive and negative attitudes and expressed regret and non-regret.

There seems to have been a pattern in the responses to the pilot items that indicated both intrinsic/symbolic and extrinsic/social motives for becoming tattooed. Intrinsic/symbolic motives refer to actions inspired by personal experiences or feelings, while extrinsic/social motives refer to actions inspired by factors outside the individual (see Table 3). This pattern of intrinsic/symbolic and extrinsic/social motivation will be reflected in the research questionnaire.

\section{Table 3}

Intrinsic/symbolic and Extrinsic/social Motives Intrinsic/symbolic Motives

To symbolize/remember an important event or person.

I wanted something that was special/meaningful to me.

To symbolize what I believe in.

To express myself/be unique.

Extrinsic/social Motives

Because they are cool/trendy.

Someone influenced me/wanted me to get one.

I like how tattoos look.

To show my parents that I have control over my own life.

Note. The intrinsic/symbolic motives are reflected in choices a, $\mathrm{d}, \mathrm{e}$, and h, and the extrinsic/social motives are reflected in choices b, c, f, and g of item 4 of the research questionnaire. 


\section{Design}

\section{Primary Study}

The primary study was causal-comparative in design, and involved data collection and analysis on quantitative data obtained from a nonrandom, crosssectional convenience sample. Participants were examined cross-sectionally in terms of tattoo presence and current or lifetime drug use at the particular time that the study was conducted. Three dimensions of the relationship between tattooing and high-risk behavior were examined in Figure 1. First, socioeconomic status (SES) and biological sex served as categorical independent variables in relation to the categorical dependent variable, tattoo presence (i.e., having or not having a tattoo, see Figure 1). Parental education attainment was used as an indicator of SES in the present study. The SES score for each individual was calculated by averaging the coded scores for his/her mother's and father's highest level of educational attainment. For data analysis purposes, the SES scores were later recalculated as follows. For each participant, the mother's coded education score was multiplied by ten, added to the father's coded education score, and then divided by two. This step was performed in order to derive a score that was better representative of the educational attainment levels characteristic of each participant's family. For example, one individual might have a mother that earned a bachelor's degree and a father that graduated high school, while another individual might have a mother and a father who both graduated from technical schools. These families are different in terms of education attainment, and could very well have different incomes that reflect this difference; however, according to the original coding scheme, both individuals would have an SES score of six. The recalculation, however, would assign an SES score of 42 to the first 
individual, while the second individual would have had a slightly lower SES score of 33. This method of SES calculation better represents the diversity in SES scores among all participants.

Second, tattoo presence became the categorical independent variable in relation to the categorical dependent variables, or risk behaviors, including: (a) current cigarette use, (b) number of cigarettes smoked per day (c) current alcohol use, (d) episodic heavy drinking, (e) current cocaine use, (f) lifetime inhalant use, (g) lifetime heroine use, (h) lifetime methamphetamine use, (i) lifetime ecstasy use, (j) lifetime number of sexual partners, (k) sexual intercourse under the influence of drugs and/or alcohol, and (1) sexual intercourse without a condom (Centers for Disease Control and Prevention [CDC], 2006). Tattoo presence as a categorical independent variable was also examined in relation to the continuous dependent variable of total risk level (see Figure 1). Each risk behavior item was given a score of 0, indicating "non-high risk," or 1, indicating "high risk;" thus, a total risk score of 0-12 was possible for each participant. Precedence for the dichotomous coding of risk behaviors into non-high risk and high risk categories was established by the CDC in the development of the YRBSS. Third, having a tattoo became a subject variable in the relationship between the continuous independent variable, motive, and the categorical dependent variable, risk behavior (see Figure 1). 


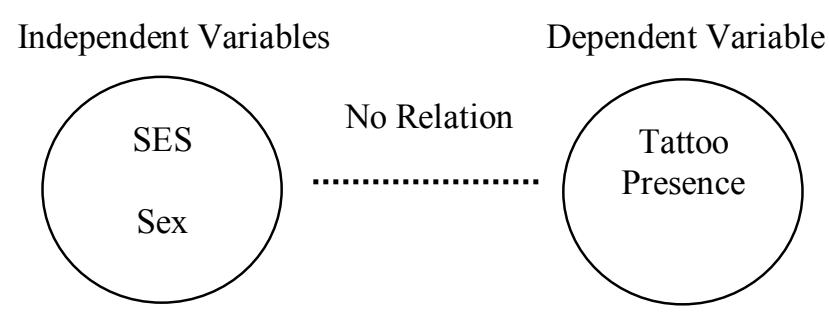

Hypothesis 1: There will be no difference in tattoo presence according to SES or biological sex.

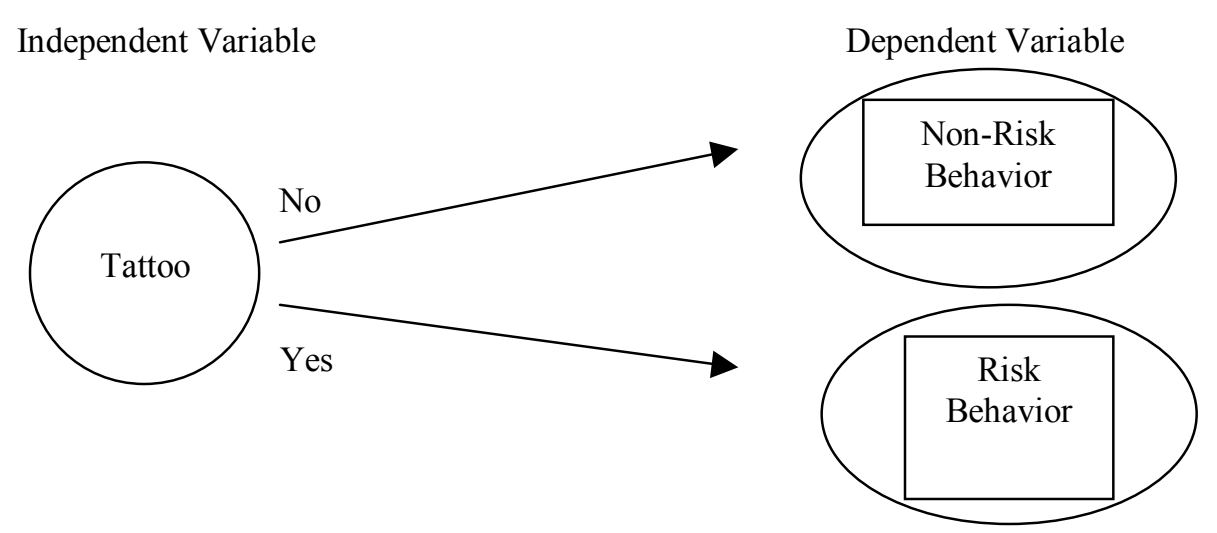

Hypothesis 2: Adolescents with tattoos will score at high risk relative to behaviors when compared to adolescents without tattoos.

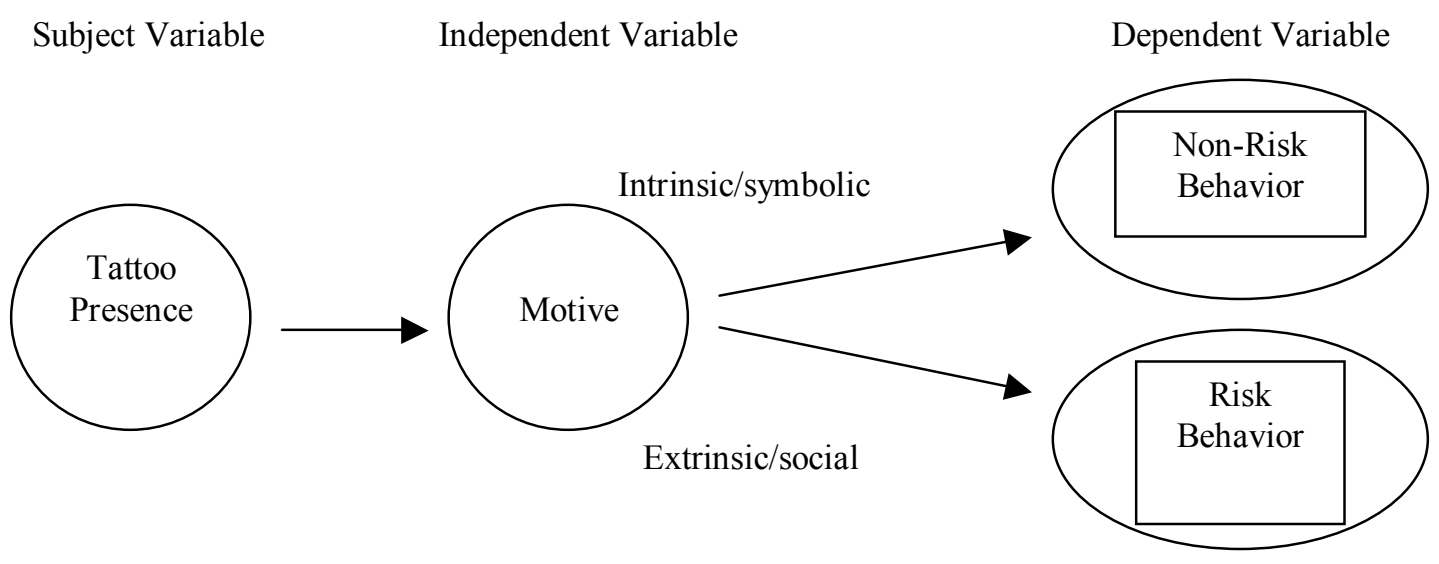

Hypothesis 3: Tattooed adolescents with extrinsic/social motives for obtaining tattoos will score at high risk relative to behaviors when compared to tattooed adolescents with intrinsic/symbolic motives for obtaining tattoos.

Figure 1. Delineation of variables for each hypothesis. 
Sample

The sample consisted of 147 male and 253 female college students between 18 and 22 years of age, with a mean age of 19.33 years. The sample was comprised of 359 Caucasian (89.8\%), 12 African American (3.0\%), 12 Asian/Pacific Islander (3.0\%), and 6 Latino/Hispanic (1.5\%) students, as well as $10(2.5 \%)$ students who marked "other," and who were of various ethnic backgrounds. Participants cited a wide variety of academic majors, with business being the most common $(n=29)$. Demographic characteristics of the sample, including SES, college rank, and major, were obtained via items $18-24$ of the questionnaire (see Appendix D). SES scores ranged from 13.5 - 80, and were divided into low (13.5 - 35), middle (35.5 - 44.5), and high (45 - 80) SES groups based on natural groups formed by the data. For additional sample characteristics, see Table 4.

\section{Recruitment of the Sample}

The nonrandom convenience sample for this study was obtained from 10 introductory level classes, including two in Child Development and Family Studies, seven in Sociology and Anthropology, and one in Communications. Participants were recruited from these particular classes for two primary reasons. First, all selected classes are required for most students on campus, which ensured that the sample represented individuals from a wide variety of academic majors, interests, and attitudes. Second, all selected classes had a large number of enrolled students, which ensured efficient data collection. An average of 108, 187, and 200 students were enrolled in the Child Development and Family Studies, Sociology and Anthropology, and Communications classes, respectively. All interested and willing students present 
on the days the questionnaires were administered, and who had not previously completed the same questionnaire in another class, were surveyed. Most students who were present completed the questionnaire, which was reflected by the overall participation rate of $87 \%$.

Table 4

Sample Characteristics by Tattooed, Non-Tattooed, and Total Participants

\begin{tabular}{|l|cc|cc|cc|}
\hline Characteristic & \multicolumn{2}{|c|}{ Tattooed } & \multicolumn{2}{c|}{ Non-Tattooed } & \multicolumn{2}{c|}{ Total } \\
\hline Sex & $n$ & $\%$ & $n$ & $\%$ & $n$ & $\%$ \\
Male & & & & & & \\
Female & 73 & 36.5 & 74 & 37.0 & 147 & 36.8 \\
& 127 & 63.5 & 126 & 63.0 & 253 & 63.3 \\
Age & & & & & & \\
18 & & & & & & \\
19 & 45 & 22.5 & 60 & 30.0 & 105 & 26.3 \\
20 & 76 & 38.0 & 68 & 34.0 & 144 & 36.0 \\
21 & 46 & 23.0 & 42 & 21.0 & 88 & 22.0 \\
22 & 21 & 10.5 & 19 & 9.5 & 40 & 10.0 \\
& 12 & 6.0 & 11 & 5.5 & 23 & 5.8 \\
Rank & & & & & & \\
Freshman & & & & & & \\
Sophomore & 92 & 46.0 & 97 & 48.5 & 189 & 47.3 \\
Junior & 64 & 32.0 & 53 & 26.5 & 117 & 29.3 \\
Senior & 29 & 14.5 & 31 & 15.5 & 60 & 15.0 \\
& 14 & 7.0 & 17 & 8.5 & 31 & 7.8 \\
Race & & & & & & \\
Caucasian & & & & & & \\
African American & 174 & 87.0 & 185 & 92.5 & 359 & 89.8 \\
Asian/Pacific Islander & 8 & 4.0 & 4 & 2.0 & 12 & 3.0 \\
Latino/a (Hispanic) & 6 & 3.0 & 6 & 3.0 & 12 & 3.0 \\
Other & 5 & 2.5 & 1 & 0.5 & 6 & 1.5 \\
& 6 & 3.0 & 4 & 2.0 & 10 & 2.5 \\
Socioeconomic Status (SES) & & & & & & \\
High & 73 & 36.5 & 76 & 38.0 & 149 & 37.3 \\
Middle & 81 & 40.5 & 78 & 39.0 & 159 & 39.8 \\
Low & 46 & 23.0 & 46 & 23.0 & 92 & 23.0 \\
\hline
\end{tabular}

Instrumentation

A 24-item self-report survey was administered to participants, and information concerning students' behavior and motives for obtaining tattoos was obtained.

Demographic characteristics of the sample were obtained via items $18-24$. The final 
analysis includes only the data from participants between the ages of 18 and 22 years;

69 surveys were discarded that did not meet these age requirements.

Motives for Obtaining Tattoos

Items 1 - 5 of the research questionnaire were included to obtain information regarding students' tattoo status as well as their motives for becoming/not becoming tattooed. Item 3 was devised to reflect the motives cited by tattooees in the pilot study. Responses from non-tattooed individuals in the pilot study were also valuable in validating these motives. Item 5, regarding intent to become tattooed in the future, was included in the survey in order to identify individuals who might become tattooed at some point in their lives. This is an important consideration, as individuals who wish to become tattooed in the future may have attitudes toward tattooing that are similar to those of tattooees. Thus, only tattooees and individuals not intending to become tattooed were included in the analysis.

\section{High-Risk Behavior}

Items 6 - 17 were adapted from the 2005 Youth Risk Behavior Surveillance System (YRBSS) developed by the CDC. The YRBSS assesses high-risk behavior according to violence, tobacco, alcohol, and drug use, sexual behavior, dietary habits, physical activity, and other health-related habits (CDC, 2006). The present study, however, employed several items regarding tobacco, drug, and alcohol use and sexual behavior. There were approximately 6 or 7 responses associated with each item. As described previously, the results obtained from these questions allowed students to be categorized dichotomously, as high risk and non-high risk, a precedent established by the CDC. On each of the 12 items designed to assess risk-taking behavior, a score of 
0 was assigned for non-high-risk behavior, and a score of 1 was assigned for high-risk behavior. The 12 risk-behavior items were scored and analyzed individually, but were also summed to yield an overall risk score of $0-12$. Items $6-17$ of the research questionnaire are shown in Appendix D with high-risk choices (which warranted a score of 1) indicated in boldface type. Brener et al. (2002) found the 1999 version of the YRBSS to have test-retest reliability according to a study of 4,619 male and female high school students. Nearly all items of the 1999 YRBSS had at least "moderate" reliability, and almost half of all items indicated a level of “substantial” reliability (p. 339). Levels of moderate and substantial reliability were defined by kappa statistics, indicating the amount of agreement from the first administration of the 1999 YRBSS to the next administration. Moderate levels of reliability were defined as kappa statistics of $41 \%$ or higher, and substantial levels of reliability were defined as kappa statistics of $61 \%$ or higher. Of particular interest to the present study, items concerning tobacco, alcohol, and drug use and sexual behavior were found to have levels of reliability significantly higher than health related items.

Procedure

The data needed for this study were collected via the 24-item self-report questionnaire discussed earlier. The data were collected in one session for each introductory level class during the spring 2007 academic semester. Administration of the data collection took place at the beginning of the class period, and lasted approximately 15 minutes. 
Prior to distribution of the surveys, students were given information about the study for which their participation was requested. Students were told that the survey procedure was part of a research study being conducted by the investigator in partial fulfillment of the requirements for a master's degree in the department of Technology, Learning, and Culture at WVU. The investigator announced that students with and without tattoos could participate in the study, but needed to meet the minimum age requirement (18 years of age) for participation. The investigator also asked students who had previously completed the same survey in another class to not complete another one. Anonymity and confidentiality were assured, and instructions on completing the survey were given. The investigator informed students that surveys would be distributed to everyone in the class, and that they could complete the surveys if they wished. Students were told that participation in the study was completely voluntary, and that they would not be penalized if they chose not to participate. The investigator assured students that if they chose to participate, they would not be required to answer all of the questions on the survey. Students were reminded to not provide any identifying information on the materials presented to them, and were informed that the survey would take them approximately 10-15 minutes to complete. Additionally, students were asked to read the Institutional Review Board (IRB) approved cover letter before completing the survey (see Appendix E).

After obtaining surveys from 200 tattooed individuals between the ages of 18 and 22 years, the investigator stopped data collection. Of the remaining surveys collected from non-tattooed individuals, 200 surveys were chosen to match the gender 
and SES score of the 200 tattooed individuals. Thus, data analyses were performed on a total of 400 individuals (200 tattooed, and 200 non-tattooed) between the ages of 18 and 22 years.

An identification number was arbitrarily assigned to each of the 400 questionnaires, and individual items were assessed as previously discussed. Any forms that contained the name of the participant, and/or indicated that the participant was under 18 years of age were discarded. Surveys that were not fully completed ( $n$ $=51)$, and/or indicated that the participant was over 22 years of age $(n=69)$ were retained, but marked unusable. Analysis of the data in relation to the research hypotheses follows.

Analytic Strategy

Hypothesis one, "There will be no difference in tattoo presence according to SES or biological sex," was assessed via cross-tabulation and chi-square analyses. Hypothesis two, "Adolescents with tattoos will score at high risk relative to behaviors when compared to adolescents without tattoos," was tested via a series of crosstabulation and chi-square analyses, loglinear analyses, and a 2x2 ANOVA analysis. Finally, hypothesis three, "Tattooed adolescents with extrinsic/social motives for obtaining tattoos will score at high risk relative to behaviors when compared to tattooed adolescents with intrinsic/symbolic motives for obtaining tattoos," was assessed via factor analysis, a series of independent samples $t$-tests, and two simple regression analyses. 


\section{CHAPTER 4}

\section{RESULTS}

All tests of the research hypotheses were conducted using an alpha level of .05. The first research hypothesis, which stated that there would be no difference in tattoo presence or absence according to SES or biological sex, was tested via two separate crosstabulation and chi-square analyses; the first analysis tested SES, and the second tested biological sex. The first analysis indicated that there was no significant relationship between tattoo presence and $\operatorname{SES}\left(\chi_{(1,400)}^{2}=.117, p=.943\right)$. Similarly, the second analysis also demonstrated a non-significant relationship between tattoo presence and gender $\left(\chi_{(1,400)}^{2}=.011, p=.917\right)$. Thus, the results of the crosstabulation and chi-square analyses supported the first hypothesis, indicating that male and female participants, as well as all individuals across SES strata, became tattooed in relatively equal numbers.

The second research hypothesis, which stated that adolescents with tattoos would score at high risk relative to behaviors when compared to adolescents without tattoos, was tested via a series of crosstabulation and chi-square analyses, a $2 \times 2$ ANOVA analysis, and a series of three-way loglinear analyses. Each of the 12 survey items assessing tobacco, alcohol, and drug use and sexual risk were analyzed via crosstabulation and chi-square analyses, according to tattoo status and gender. The total risk level (i.e., the sum of the scores for each of the 12 risk items) was analyzed via a $2 \times 2$ ANOVA analysis. Each risk behavior item was given a score of 0 , indicating non-high risk, or 1, indicating high risk; thus, a total risk score of $0-12$ was possible for each participant. 
Overall, hypothesis two was supported by the analyses. When compared with their non-tattooed peers, a significantly larger number of tattooed participants reported engagement in high-risk behaviors, including current cigarette use $\left(\chi_{(1)}^{2}=\right.$ $25.319, p=.000)$, number of cigarettes smoked per day $\left(\chi_{(1)}^{2}=2.842, p=.046\right)$, current alcohol use $\left(\chi_{(1)}^{2}=10.632, p=.001\right)$, episodic heavy drinking $\left(\chi_{(1)}^{2}=5.766, p\right.$ $=.008)$, current cocaine use $\left(\chi_{(1)}^{2}=3.456, p=.032\right)$, lifetime inhalant use $\left(\chi_{(1)}^{2}=\right.$ $12.754, p=.000)$, lifetime heroin use $\left(\chi_{(1)}^{2}=4.592, p=.016\right)$, lifetime methamphetamine use $\left(\chi_{(1)}^{2}=4.476, p=.017\right)$, lifetime ecstasy use $\left(\chi_{(1)}^{2}=6.288, p\right.$ $=.006)$, lifetime number of sexual partners $\left(\chi_{(1)}^{2}=20.521, p=.000\right)$, and sexual intercourse under the influence of drugs and/or alcohol $\left(\chi_{(1)}^{2}=10.819, p=.001\right)$, as shown in Table 5. Similarly, the 2x2 ANOVA analysis also showed that tattooed individuals were involved in risk-taking behaviors to a higher degree than their nontattooed peers in terms of total risk level $\left(F_{(1,396)}=34.144, p=.000\right)$, and is illustrated in Table 6.

Table 5

Tattooed and Non-Tattooed Participants' Engagement in Significant High-Risk Behaviors

\begin{tabular}{lcccccc}
\hline & \multicolumn{7}{c}{ Tattooed } & \multicolumn{2}{c}{ Non-Tattooed } & \\
\cline { 2 - 7 } \multicolumn{1}{c}{ High-Risk Behavior } & $n$ & $\%$ & $n$ & $\%$ & $\chi^{2}$ & $p$ \\
\hline Current cigarette use & 94 & 47.0 & 46 & 23.0 & 25.319 & .000 \\
Number of cigarettes smoked per day & 7 & 3.5 & 2 & 1.0 & 2.842 & .046 \\
Current alcohol use & 187 & 93.5 & 166 & 83.0 & 10.632 & .001 \\
Episodic heavy drinking & 159 & 79.5 & 138 & 69.0 & 5.766 & .008 \\
Current cocaine use & 17 & 8.5 & 8 & 4.0 & 3.456 & .032 \\
Lifetime inhalant use & 35 & 17.5 & 12 & 6.0 & 12.754 & .000 \\
Lifetime heroin use & 7 & 3.5 & 1 & 0.5 & 4.592 & .016 \\
Lifetime methamphetamine use & 14 & 7.0 & 5 & 2.5 & 4.476 & .017 \\
Lifetime ecstasy use & 31 & 15.5 & 15 & 7.5 & 6.288 & .006 \\
Lifetime number of sexual partners & 111 & 55.5 & 66 & 33.0 & 20.521 & .000 \\
Sexual intercourse under the influence & 74 & 37.0 & 44 & 22.0 & 10.819 & .001 \\
\hline Note. Percentages indicate the portion of participants within each tattoo status who reported &
\end{tabular}


Table 6

Analysis of Variance for Total Risk Level

\begin{tabular}{lccc}
\hline Source & df & $F$ & $p$ \\
\hline Between Subjects & & & \\
\hline Tattoo Status (T) & 1 & $34.144^{* *}$ & .000 \\
Gender (T) & 1 & $8.246^{* *}$ & .002 \\
T x G & 1 & .181 & .336 \\
error & 396 & $(3.824)$ & \\
\hline
\end{tabular}

Note. Values enclosed in parentheses represent mean square errors.

$* * \mathrm{p}<.01$

The crosstabulation and chi-square analyses used to test hypothesis two also demonstrated a significant association between gender and several high risk behaviors that warrants mentioning. When compared to females, higher numbers of male participants reported engagement in current cigarette use $\left(\chi_{(1)}^{2}=4.312, p=.019\right)$, number of cigarettes smoked per day $\left(\chi_{(1)}^{2}=3.545, p=.030\right)$, episodic heavy drinking $\left(\chi_{(1)}^{2}=5.461, p=.010\right)$, current cocaine use $\left(\chi_{(1)}^{2}=4.251, p=.020\right)$, lifetime inhalant use $\left(\chi_{(1)}^{2}=4.694, p=.015\right)$, lifetime methamphetamine use $\left(\chi_{(1)}^{2}=\right.$ $3.837, p=.025)$, and lifetime ecstasy use $\left(\chi_{(1)}^{2}=2.743, p=.049\right)$ as shown in Table 7. The 2x2 ANOVA analysis used to test hypothesis two also indicated that males displayed higher overall risk levels $\left(\mathrm{F}_{(1,396)}=8.246, p=.002\right)$ than their female counterparts, and is highlighted in Table 6.

Finally, three-way loglinear analyses were performed for each individual high-risk behavior to assess the relationship between tattoo status, gender, and a given high-risk behavior. Results of all loglinear analyses were non-significant, suggesting that the interaction of tattoo status and gender was not significantly related to engagement in high-risk behavior. 
Table 7

Male and Female Participants' Engagement in Significant High-Risk Behaviors

\begin{tabular}{lcccccc}
\hline & \multicolumn{3}{c}{ Male } & \multicolumn{1}{c}{ Female } & \\
\cline { 2 - 7 } \multicolumn{1}{c}{ High-Risk Behavior } & $n$ & $\%$ & $n$ & $\%$ & $\chi^{2}$ & $p$ \\
\hline Current cigarette use & & & & & & \\
Number of cigarettes smoked per day & 61 & 41.5 & 79 & 31.2 & 4.312 & .019 \\
Episodic heavy drinking & 119 & 81.0 & 178 & 70.4 & 5.461 & .010 \\
Current cocaine use & 14 & 9.5 & 11 & 4.3 & 4.251 & .020 \\
Lifetime inhalant use & 24 & 16.3 & 23 & 9.1 & 4.694 & .015 \\
Lifetime methamphetamine use & 11 & 7.5 & 8 & 3.2 & 3.837 & .025 \\
Lifetime ecstasy use & 22 & 15.0 & 24 & 9.5 & 2.743 & .049 \\
\hline Note. Percentages indicate the portion of participants within each gender who are engaging in the given \\
risk behaviors.
\end{tabular}

A test of the third research hypothesis, which stated that tattooed adolescents with extrinsic/social motives for obtaining tattoos would score at high risk relative to behaviors when compared to tattooed adolescents with intrinsic/symbolic motives for obtaining tattoos, was conducted via factor analysis, independent samples $t$-tests, and regression analyses. Statistical tests for this hypothesis were only carried out on the tattooed portion ( $n=199$, rather than 200 , due to listwise exclusion) of the sample. The first step in testing hypothesis three was to extract factors from the eight motives to become tattooed via factor analysis (Field, 2005). The second step in testing hypothesis three, once factors were extracted, was to test the association between each factor and the individual risk items, including total risk level. A series of $t$-tests were used to analyze the relationships between each factor and each risk item. Simple regression analyses were used to determine the association between each factor and the total risk level. A third step in analysis was taken to examine the associations between each individual motive and the individual risk items, including total risk level. A series of $t$-tests were used to examine the association between each 
motive and each risk item. Simple regression analyses were used to examine the association between each motive and the total risk level.

Principle components extraction with promax rotation was performed on the eight variables that reflected tattooed participants' motives to become tattooed.

Preliminary analyses, including the correlation matrix (see Table 8), Kaiser-MeyerOlkin (KMO) test, and anti-image matrices indicated that the sample of tattooed students was sufficient for factor analysis. Three factors emerged from the extraction of factors with eigenvalues greater than one. Before rotation, these factors accounted for $62.8 \%$ of the total variance. Communalities after extraction were fairly high, and reflected that, on average, $62.8 \%$ of the variance in each variable could be explained by the three extracted factors.

Table 8 Correlation Matrix produced by Factor Analysis on the Total Tattooed Sample

Correlation Matrix ${ }^{2, b}$

\begin{tabular}{|c|c|c|c|c|c|c|c|c|c|}
\hline & & friend & be unique & $\begin{array}{l}\text { like how } \\
\text { they look }\end{array}$ & $\begin{array}{c}\text { symbolize } \\
\text { person/event }\end{array}$ & $\begin{array}{l}\text { special } / \mathrm{m} \\
\text { eaningful }\end{array}$ & cool/trendy & parents & $\begin{array}{l}\text { symbolize } \\
\text { beliefs }\end{array}$ \\
\hline \multirow[t]{8}{*}{ Correlation } & friend & 1.000 & -.050 & .033 & -.003 & -.076 & .288 & .128 & .060 \\
\hline & be unique & -.050 & 1.000 & .381 & .143 & .159 & .103 & .090 & .199 \\
\hline & like how they look & .033 & .381 & 1.000 & -.066 & .052 & .344 & .102 & .067 \\
\hline & symbolize person/event & -.003 & .143 & -.066 & 1.000 & .592 & -.248 & -.036 & .478 \\
\hline & special/meaningful & -.076 & .159 & .052 & .592 & 1.000 & -.139 & -.036 & .440 \\
\hline & cool/trendy & .288 & .103 & .344 & -.248 & -.139 & 1.000 & .238 & -.082 \\
\hline & parents & .128 & .090 & .102 & -.036 & -.036 & .238 & 1.000 & -.021 \\
\hline & symbolize beliefs & .060 & .199 & .067 & .478 & .440 & -.082 & -.021 & 1.000 \\
\hline \multirow[t]{7}{*}{ Sig. (1-tailed) } & friend & & .244 & .320 & .486 & .142 & .000 & .036 & .200 \\
\hline & be unique & .244 & & .000 & .022 & .013 & .073 & .102 & .002 \\
\hline & like how they look & .320 & .000 & & .175 & .234 & .000 & .075 & .173 \\
\hline & symbolize person/event & .486 & .022 & .175 & & .000 & .000 & .308 & .000 \\
\hline & special/meaningful & .142 & .013 & .234 & .000 & & .025 & .308 & .000 \\
\hline & cool/trendy & .000 & .073 & .000 & .000 & .025 & & .000 & .125 \\
\hline & symbolize beliefs & .200 & .002 & .173 & .000 & .000 & .125 & .387 & \\
\hline
\end{tabular}

a. Determinant $=.260$

b. tattoo status $=$ yes

Note. Adapted from statistical analysis output using SPSS statistical software. Column and row headings indicate motives to become tattooed, and are reflective of choices a-h of item 4 of the research questionnaire (see Appendix D). 
With the reproduced correlation matrix showing only slightly more than half $(53 \%)$ of all residuals with absolute values greater than .05 , the factor model was a sufficient representation of the data (Field, 2005). Pattern and structure matrices following oblique rotation were examined, and it was determined that they yielded similar results; both matrices displayed the same three factors, with all variables loading onto at least one of the three extracted factors. All factors were comprised of variables with factor loadings of .4 or greater. Extracted factors one, two, and three were interpreted as intrinsic/symbolic motives, personal aesthetic motives, and extrinsic/social motives, respectively. Table 9 shows the factor loadings, communalities, and percents of variance for each of the three extracted factors after rotation.

Table 9

Factor Loadings, Communalities, and Percent Variance for Factors 1, 2, and 3

\begin{tabular}{|c|c|c|c|c|}
\hline & $\begin{array}{c}\text { Factor 1 } \\
\text { (Intrinsic/ } \\
\text { symbolic } \\
\text { motives) }\end{array}$ & $\begin{array}{c}\text { Factor } 2 \\
\text { (Personal } \\
\text { aesthetic } \\
\text { motives) }\end{array}$ & $\begin{array}{c}\text { Factor 3 } \\
\text { (Extrinsic/ } \\
\text { social } \\
\text { motives) }\end{array}$ & \\
\hline Variable & & Factor loadings & & Communalities \\
\hline Friend & & & .852 & .704 \\
\hline Be unique & & .787 & & .649 \\
\hline Like how they look & & .813 & & .700 \\
\hline Symbolize person/event & .860 & & & .743 \\
\hline Special/meaningful & .799 & & & .665 \\
\hline Cool/trendy & & & .622 & .645 \\
\hline Parents & & & .538 & .315 \\
\hline \multirow[t]{3}{*}{ Symbolize beliefs } & .778 & & & .604 \\
\hline & & Percent variance & & \\
\hline & 26.393 & 19.383 & 18.983 & \\
\hline
\end{tabular}

Note. Factor loadings reflect the values obtained by the pattern matrix. The pattern matrix was chosen for presentation over the structure matrix because it displays unique variable contributions to each factor. Communalities and percent variance reflect values obtained after factor extraction and rotation.

Two additional factor analyses (principle components extraction with promax rotation) were conducted by gender to determine whether similar factors were 
extracted when either males or females were excluded from the sample. In terms of extraction and rotation, the male and female samples varied little from the total subsample of all tattooed individuals. While three factors were also extracted in the male and female subsamples, a difference occurred in the factor loading. Specifically, for the male subsample, factor three was only comprised of one motive, rather than two, as in the extraction of the total sample.

Results of the factor analyses by gender must be interpreted with caution, however, due to the small sample sizes created by splitting the total sample. The small number of males $(n=73)$, in particular, could render the sample inappropriate for factor analysis. According to Field (2005), if the sample size is at least 10 times greater than the number of variables being examined (in the case of the current study, that number would be 80), then factor analysis could be sufficient in testing the sample. In light of this possible limitation, only the factor scores obtained from the factor analysis of the total tattooed subsample was used in further tests of the third research hypothesis.

The relationship between each individual motive and each risk behavior item, including the total risk level, was evaluated. The $t$-tests showed that each motive to become tattooed was significantly related in some way to one or more risk behavior item. Based on several behaviors, risk-takers, in comparison to non-risk-takers, rated the following motives as more important to them in their decisions to become tattooed: (a) to express myself/be unique, (b) to symbolize an important person/event, and (c) to show my parents that I have control over my own life. Conversely, risktakers, when compared to non-risk-takers, rated the following motives as less 
important to them in their decisions to become tattooed: (a) a friend/someone I know wanted me to get one, (b) I like the way they look, (c) I wanted something that was special/meaningful to me, (d) I think tattoos are cool/trendy, (e) I wanted to symbolize what I believe in. These significant relationships are presented in greater detail in Table 10.

\section{Table 10}

Significant Results of t-test for Motives with Risk-Behavior Items as Grouping Variables

\begin{tabular}{|c|c|c|c|c|c|c|c|}
\hline Variable & Risk-behavior & Group & df & $t$ & $p$ & M & SE \\
\hline \multirow[t]{2}{*}{ Friend } & Condom use & Non-risk & 146.869 & 1.692 & .047 & 1.6544 & .09357 \\
\hline & & Risk & & & & 1.4063 & .11295 \\
\hline \multirow[t]{6}{*}{ Be unique } & $\begin{array}{l}\text { Number of } \\
\text { cigarettes per day }\end{array}$ & Non-risk & 198 & -2.114 & .018 & 3.5648 & .08989 \\
\hline & & Risk & & & & 4.5714 & .29738 \\
\hline & $\begin{array}{l}\text { Lifetime inhalant } \\
\text { use }\end{array}$ & Non-risk & 198 & -1.799 & .037 & 3.5273 & .09898 \\
\hline & & Risk & & & & 3.9429 & .18308 \\
\hline & $\begin{array}{l}\text { Lifetime heroin } \\
\text { use }\end{array}$ & Non-risk & 9.240 & -3.457 & .004 & 3.5751 & .09075 \\
\hline & & Risk & & & & 4.2857 & .18443 \\
\hline \multirow[t]{2}{*}{$\begin{array}{l}\text { Like how } \\
\text { they look }\end{array}$} & $\begin{array}{l}\text { Lifetime ecstasy } \\
\text { use }\end{array}$ & Non-risk & 37.544 & 1.820 & .039 & 4.0476 & .07821 \\
\hline & & Risk & & & & 3.6129 & .22565 \\
\hline \multirow{2}{*}{$\begin{array}{l}\text { Symbolize } \\
\text { person/ } \\
\text { event }\end{array}$} & $\begin{array}{l}\text { Number of } \\
\text { cigarettes per day }\end{array}$ & Non-risk & 192 & -12.152 & .000 & 3.6788 & .10873 \\
\hline & & Risk & & & & 5.0000 & .00000 \\
\hline \multirow[t]{4}{*}{$\begin{array}{l}\text { Special/ } \\
\text { meaningful }\end{array}$} & $\begin{array}{l}\text { Current alcohol } \\
\text { use }\end{array}$ & Non-risk & 23.817 & 3.134 & .003 & 4.7692 & .12163 \\
\hline & & Risk & & & & 4.3155 & .07851 \\
\hline & $\begin{array}{l}\text { Drugs/ alcohol } \\
\text { before sex }\end{array}$ & Non-risk & 198 & 1.758 & .040 & 4.4444 & .08623 \\
\hline & & Risk & & & & 4.1757 & .13518 \\
\hline \multirow[t]{4}{*}{$\begin{array}{l}\text { Cool// } \\
\text { trendy }\end{array}$} & $\begin{array}{l}\text { Current cigarette } \\
\text { use }\end{array}$ & Non-risk & 198 & 1.787 & .038 & 2.6604 & .11444 \\
\hline & & Risk & & & & 2.3617 & .12181 \\
\hline & $\begin{array}{l}\text { Lifetime ecstasy } \\
\text { use }\end{array}$ & Non-risk & 53.819 & 1.885 & .033 & 2.5740 & .09446 \\
\hline & & Risk & & & & 2.2258 & .15869 \\
\hline \multirow[t]{2}{*}{ Parents } & $\begin{array}{l}\text { Lifetime number } \\
\text { of sexual partners }\end{array}$ & Non-risk & 197.966 & -1.653 & .050 & 1.4045 & .09551 \\
\hline & & Risk & & & & 1.6396 & .10538 \\
\hline \multirow[t]{2}{*}{$\begin{array}{l}\text { Symbolize } \\
\text { beliefs }\end{array}$} & $\begin{array}{l}\text { Lifetime number } \\
\text { of sexual partners }\end{array}$ & Non-risk & 198 & 1.835 & .034 & 3.1573 & .16367 \\
\hline & & Risk & & & & 2.7748 & .13281 \\
\hline
\end{tabular}


The simple regression analyses used to test the associations between each individual motive and the total risk level yielded non-significant results, with the exception of total risk level and the motive "to symbolize what I believe in" $\left(F_{(1,198)}=\right.$ $4.446, p=.018)$. According to the analyses, this motive was significantly predictive of total risk level, and is shown in Table 11.

\section{Table 11}

Simple Regression Analyses between Motives and Total Risk Level $(n=199)$

\begin{tabular}{lccc}
\hline Predictor variable & $\boldsymbol{B}$ & $\boldsymbol{S} \boldsymbol{B}$ & $\boldsymbol{\beta}$ \\
\hline Friend & .098 & .143 & .049 \\
Be unique & .026 & .119 & .015 \\
Like how they look & -.044 & .140 & -.023 \\
Symbolize person/ & -.060 & .099 & -.043 \\
event & & \\
Special/ meaningful & -.196 & .141 & -.098 \\
Cool/ trendy & -.032 & .125 & -.018 \\
Parents & .081 & .145 & .040 \\
Symbolize beliefs & -.210 & .100 & $-.148^{*}$ \\
\hline Note. $\mathrm{R}^{2}$ scores for each regression analysis are $.002, .000, .001, .002, .010, .000, .002$, and .022, \\
respectively. \\
${ }^{* p}<.05$
\end{tabular}

Further analysis of hypothesis three included a series of $t$-tests which were performed on each factor in relation to each risk behavior item. The significant results of this analysis are presented in Table 12. Factor one (intrinsic/symbolic motives) was significantly related to current alcohol use $\left(t_{(197)}=1.977, p=.025\right)$. This indicated that, based on current alcohol use, intrinsic/symbolic motives were not as important to risk-takers as compared to non-risk takers. Factor three (extrinsic/social motives) was also significantly related to current cigarette use $\left(t_{(197)}\right.$ $=1.860, p=.032)$ and number of lifetime sexual partners $\left(t_{(196.978)}=-1.886, p=.031\right)$. These results indicated that extrinsic/social motives were more important to risktakers when risk-behavior was based on current cigarette use, but not when it was 
based on number of lifetime sexual partners. Simple regression analyses were also conducted to evaluate the association between each factor and the total risk level for tattooed participants. Each simple regression analysis yielded non-significant results, indicating that intrinsic/symbolic motives $\left(F_{(1,197)}=2.346, p=.127\right)$, personal aesthetic motives $\left(F_{(1,197)}=.080, p=.778\right)$, and extrinsic/social motives $\left(F_{(1,197)}\right.$ $=.128, p=.720$ ) were not significantly predictive of risk behavior, as depicted in

Table13.

\section{Table 12}

Significant Results of t-test for Factors with Risk-Behavior Items as Grouping Variables

\begin{tabular}{|c|c|c|c|c|c|c|c|}
\hline Variable & Risk-behavior & Group & df & $t$ & $p$ & $\mathbf{M}$ & SE \\
\hline $\begin{array}{l}\text { Factor 1 } \\
\text { Intrinsic/ } \\
\text { symbolic } \\
\text { motives }\end{array}$ & Current alcohol use & $\begin{array}{l}\text { Non-risk } \\
\text { Risk }\end{array}$ & 197 & 1.977 & .025 & $\begin{array}{l}.5261497 \\
-.0367739\end{array}$ & $\begin{array}{l}.21601085 \\
.07369332\end{array}$ \\
\hline \multirow{2}{*}{$\begin{array}{l}\text { Factor } 3 \\
\text { Extrinsic/ } \\
\text { social } \\
\text { motives }\end{array}$} & Current cigarette use & $\begin{array}{c}\text { Non-risk } \\
\text { Risk }\end{array}$ & 197 & 1.860 & .032 & $\begin{array}{l}.1239543 \\
-.1384596\end{array}$ & $\begin{array}{l}.10369642 \\
.09395017\end{array}$ \\
\hline & $\begin{array}{l}\text { Lifetime number of sexual } \\
\text { partners }\end{array}$ & $\begin{array}{c}\text { Non-risk } \\
\text { Risk }\end{array}$ & 196.978 & -1.886 & .031 & $\begin{array}{r}-.1446367 \\
.1170243\end{array}$ & $\begin{array}{l}.09326860 \\
.10271580\end{array}$ \\
\hline
\end{tabular}

\section{Table 13}

Simple Regression Analyses between Factor Scores and Total Risk Level $(n=199)$

\begin{tabular}{lccc}
\hline Predictor variable & $\boldsymbol{B}$ & $\boldsymbol{S E} \boldsymbol{B}$ & $\boldsymbol{\beta}$ \\
\hline $\begin{array}{l}\text { Factor 1 } \\
\text { Intrinsic/symbolic } \\
\text { motives }\end{array}$ & -.227 & .148 & -.108 \\
$\begin{array}{l}\text { Factor 2 } \\
\text { Personal aesthetic }\end{array}$ & -.042 & .149 & -.020 \\
$\begin{array}{l}\text { motives } \\
\text { Factor 3 }\end{array}$ & & \\
$\begin{array}{l}\text { Extrinsic/social } \\
\text { motives }\end{array}$ & .053 & .149 & .026 \\
\hline Note. $\mathrm{R}^{2}$ scores for each regression analysis are $.012, .000$, and .001, respectively.
\end{tabular}


Hypothesis three was partially supported by factor analysis - factors, which could indicate underlying motives, were extracted. Further testing of this hypothesis also showed partial support for an association between extracted factors and high-risk behavior, as well as between individual motives and high-risk behavior. 


\section{CHAPTER 5}

\section{DISCUSSION}

Interpretation of the Results

The main objective of the current research study was to examine adolescents' motives for becoming tattooed, and whether certain motives would be more likely related to high risk behaviors. It was emphasized that adolescent tattooees are a heterogeneous group that has received little attention in terms of its diversity. For instance, while research has shown that adolescent tattooing is related to high risk behavior, not all tattooed adolescents engage in such behavior (Roberts \& Ryan, 2002). In accordance with Brooks et al.'s (2003) discussion of motive and Faules and Alexander's (1978) proposition that external expressions are reflective of internal states, it was proposed that the examination of adolescents' motives for becoming tattooed could help illuminate behavioral differences between individual tattooees.

In pursuit of the main research objective, three hypotheses were derived to examine the relationship between tattooing and high-risk behavior. The first hypothesis stated that there would be no difference in tattoo presence or absence according to SES or biological sex. Crosstabulation and chi-square analyses showed no significant difference in tattoo status among SES strata and between males and females; hence, the hypothesis was accepted. Although participants were from a variety of socioeconomic backgrounds, their choice to become or not become tattooed seemed to be independent of their SES. This finding is contradictory to that of Roberts and Ryan (2002), who found that tattooed adolescents tended to be of lower SES. A difference in sample characteristics could possibly explain the contradictory 
findings between the studies. While Roberts and Ryan examined a large sample of adolescents in junior and senior high schools across the United States, the present study examined college students, who could represent a very different group of adolescents, especially in terms of values. Not all adolescents attend college, but those that do likely share some of the same values or goals toward higher education. This shared ideal, between college students and even their parents, could account for the homogeneity of the sample used in the current study. Conversely, most adolescents attend junior high and high school, so it is not surprising that the sample used by Roberts and Ryan was rather diverse in terms of ideals and attitudes.

Tests of the first hypothesis also showed that male and female participants became tattooed in relatively equal numbers. This finding was congruent with the research of Drews et al. (2000) and Sanders (1991/1999). Sanders asserted that adolescent males and females have different reasons for becoming tattooed and choose different designs and locations, but the practice is just as prevalent among both sexes. In contrast, Carroll et al. (2002) found that females were more likely to become tattooed, while Houghton et al. (1996) asserted that males were more likely to become tattooed. Research showed that tattooing has become more prevalent among females in the past decade (Atkinson, 2003; Miller, 1999), so perhaps Houghton et al.'s conclusion was accurate when it was presented over a decade ago. Research also showed that females were more likely to report body modification than males (Brooks et al., 2003), which could account for the research findings of Carroll et al. 
The second hypothesis stated that adolescents with tattoos would display higher degrees of risk-taking behavior than adolescents without tattoos. Individual high-risk behaviors were assessed via a series of crosstabulation and chi-square analyses, and overall risk level was assessed via a 2x2 ANOVA analysis. Risky behaviors were analyzed by both tattoo status and gender. Results of statistical analysis showed that adolescent participants with tattoos engaged in high-risk behaviors in higher numbers than their non-tattooed peers on the majority of behaviors examined. Of the 12 behaviors examined in the current study, tattooed participants showed higher participation in current cigarette use, current alcohol use, episodic heavy drinking, lifetime inhalant use, lifetime heroin use, lifetime methamphetamine use, lifetime ecstasy use, lifetime number of sexual partners, and sexual intercourse under the influence of drugs and/or alcohol. Results of the $2 \times 2$ ANOVA analysis on overall risk level also showed that tattooed participants were involved in risky behaviors to a higher degree than non-tattooed participants.

Evidence of a relationship between tattooing and high-risk behavior confirmed previous research on adolescent body modification and high-risk behavior that had been conducted in the domains of tobacco, alcohol, and drug use and sexual behavior, as well as other areas of behavior (Brooks et al., 2003; Carroll et al., 2002; Deschesnes et al., 2006; Roberts \& Ryan, 2002). This finding also coincided with theoretical literature that supported "risk-behavior as a syndrome" as well as "riskbehavior as situation-specific" explanations for the association between body modification and high-risk behavior (Arnett, 1998; Byrnes, 2003; Donovan \& Jessor, 1985). According to the risk-behavior as a syndrome approach, involvement in a 
given risky behavior is often associated with engagement in other behaviors that place one at risk for harm. Tattooing is sometimes considered a high-risk behavior that could be related to other risky activities, including alcohol or drug use (Armstrong \& Pace Murphy, 1999; Houghton et al., 1996). According to the situation-specific approach to risk-behavior, the same factors that could influence an adolescent to engage in tattooing (i.e., peer influence, heightened sensation-seeking in adolescence, etc.) might also influence his/her involvement in other high-risk behaviors. In light of the current research findings, hypothesis two was also accepted.

It was mentioned that another finding emerged in the test of the second hypothesis. Data collected in the current research study indicated that male participants engaged in risk-taking behaviors in higher numbers than female participants in terms of current cigarette use, episodic heavy drinking, current cocaine use, lifetime inhalant use, and lifetime methamphetamine use. Once again, the $2 \times 2$ ANOVA analysis of overall risk level showed that male participants were involved in high-risk behaviors to a higher degree than female participants. These findings confirm Houghton et al.'s (1996) research that showed males to be more likely to engage in high risk behavior. Additionally, results of the 2005 YRBSS showed participation in episodic heavy drinking and current cocaine use to be significantly higher among males (CDC, 2006). According to Arnett (1995), the higher rate of participation in high-risk behaviors among males could be explained by adolescent hormonal fluctuations that may contribute to heightened aggression and reckless behavior in males. Drews et al. (2000) on the other hand, found that it was not the 
rate of engagement in high-risk behaviors that differed according to gender; rather, males and females engaged in different types of risky behaviors.

In light of the findings on the independent associations of tattoo status and gender and high-risk behavior, three-way loglinear analyses were conducted to assess the relationship between the combined effect of tattoo status and gender on high-risk behavior. The results of the loglinear analyses indicated that there was no significant association between all three variables. Thus, a particular combination of tattoo status and gender does not necessarily mean that one is more likely to engage in risky behaviors than another individual with a different combination of tattoo status and gender.

Finally, the third research hypothesis stated that tattooed adolescents with extrinsic/social motives for obtaining tattoos would display higher degrees of risktaking than tattooed adolescents with intrinsic/symbolic motives for obtaining tattoos. In order to test this hypothesis, it was necessary to determine whether or not motives to become tattooed could, in fact, be grouped into intrinsic/symbolic and extrinsic/social categories, as proposed by the literature (Atkinson, 2003; Brooks et al., 2003). Consequently, factor analysis was chosen as a method of determining the presence of any variables (i.e., motives for becoming tattooed) that might correlate with one another due to latent factors such as the internal and external intentions posited by hypothesis three (Tabachnick \& Fidell, 2001).

Factor analysis of the data showed that the particular motives examined in the current research study (only among tattooed participants) could be grouped into three factors. While it was surmised that tattooed individuals would either cite mostly 
intrinsic/symbolic motives or mostly extrinsic/social motives for becoming tattooed, the nature of factors extracted seemed to represent something a little different. Factor one included motives that seemed to reflect intrinsic or symbolic reasons to become tattooed, such as (a) to symbolize a person or event in one's life, (b) to represent something special or meaningful, or (c) to symbolize one's spiritual or religious beliefs. Factor two included motives that perhaps reflected personal aesthetic reasons to become tattooed, such as (a) to be unique, or (b) the individual simply likes how tattoos look. Factor three included motives that could be classified as extrinsic or social reasons to become tattooed, such as (a) a friend wanted the individual to get a tattoo, (b) the individual thinks tattoos are cool or trendy, or (c) the individual wants to show his/her parents that he/she is in control. Therefore, motives for becoming tattooed emerged that were somewhat similar to those predicted by the third research hypothesis.

Factor one motives could be compared to the intrinsic/symbolic motives cited by Atkinson (2003) and Brooks et al. (2003); these are the motives that represent individuals who become tattooed for personal, reflective, or symbolic purposes. Factor three motives, then, could be compared to the extrinsic/social motives cited by Atkinson and Brooks et al.; these motives represent individuals who use tattooing as a response to others' actions or desires, or as a means of social identification. A third and unexpected motive classification also emerged. Factor two, or personal aesthetic motives, could represent individuals who obtain tattoos as a means of self expression, or who enjoy the artistic value of tattoos. 
The relationship between each individual motive and each risk behavior item was evaluated using a series of $t$-tests. A simple regression analysis was also used to assess the relationships between each motive and the total risk level. According to $t$ test results, motives including: (a) to express myself/be unique, (b) to symbolize an important person/event, and (c) to show my parents that I have control over my own life, were more important to risk-takers than to their non-risk-taking counterparts. These motives reflected all three extracted factors, and thus did not fully support the third hypothesis.

Results of the $t$-tests also indicated that more non-risk-takers, when compared to risk-takers, cited the following motives as important to their decision to become tattooed: (a) a friend/someone I know wanted me to get one, (b) I like the way they look, (c) I wanted something that was special/meaningful to me, (d) I think tattoos are cool/trendy, (e) I wanted to symbolize what I believe in. Again, these motives were reflective of all three extracted factors, and thus did not completely support hypothesis three. According to the simple regression analyses, only one motive, "to symbolize what I believe in," was significantly predictive of the total risk level.

Further analysis of hypothesis three included a series of independent samples $t$-tests, which were performed on each factor in relation to each risk behavior item. Factor scores and total risk behavior were also compared using simple regression analyses. While results of the regression analyses were non-significant, several $t$-tests resulted in significant findings. According to these analyses, intrinsic/symbolic motives (in the domain of current alcohol use) were more important to non-risk-takers, when compared to their risk-taking counterparts; this finding is congruent with 
hypothesis three. The $t$-tests also indicated that extrinsic/social motives were important to both risk-takers and non-risk-takers, in relation to different domains of risk-behavior (i.e., current cigarette use, and lifetime number of sexual partners, respectively). Although these findings do not completely support hypothesis three, there is something to be said for the significance of the analyses. The two factors displaying statistically significant relationships with high-risk behaviors are similar to the factors originally predicted by the literature and hypothesis three. Associations between intrinsic/symbolic and extrinsic/social motives and risk behavior did not appear exactly as predicted; however, evidence of an interesting relationship has surfaced.

The various methods used to test hypothesis three demonstrated that it was partially supported by statistical analysis. While there seemed to be an overall lack of association between motive and high risk behavior, this finding could be explained by the homogeneity (in terms of risk behavior) of the sample. Hypothesis three only included the tattooed portion of the total sample, which (according to the test of hypothesis two) was predominantly comprised of risk takers. With a relatively large portion of the subsample being risk takers, it is unlikely that a strong association would emerge between tattoo motives and the risk behavior categories.

Although there may not be a strong association between motive and high risk behavior, the emergence of intrinsic/symbolic, personal aesthetic, and extrinsic/social motives is certainly important. The presence of these individual motives indicates that there is some variable or group of variables on which they converge; it is now a matter of determining what the variable or variables may be. In light of the present 
findings, the variable is not likely to be high risk behavior. Thus, the association between motive and other constructs (e.g., identity) must be investigated.

\section{Limitations of the Study}

The current research study had several limitations related to the generalizability of the findings. First, sample diversity was an issue. Because the sample for the present study was comprised of college students of predominantly Caucasian American backgrounds, diversity in values, experiences, and race/ethnicity was not attained. In terms of values and experiences, college students represent a specialized group of adolescents. Many adolescents in college have similar values for education and, while no two people have the same life experiences, many students are influenced by the college environment as a whole. In this setting, many students experience living away from their families, making their own decisions, and are exposed to a fairly liberal environment.

Second, although the total sample size of 400 participants was adequate for statistical analysis, perhaps a larger sample would have been more representative of the population of adolescents as a whole. For example, while factor analysis tests indicated that the subsample of tattooed participants was adequate for examination, these criteria were minimally attained and could have yielded more representative results from a larger sample size.

Third, while much research has been conducted on adolescent tattooees in the domains of tobacco, alcohol, and drug use and sexual behavior (Brooks et al., 2003; Carroll et al., 2002; Deschesnes et al., 2006; Roberts \& Ryan, 2002), the study of a 
wider variety of risk behaviors across other domains could have also contributed to the generalizability of the findings.

Fourth, the measure used to assess motives to become and not become tattooed was not representative of all adolescents. In order to quantify individuals' reasons for engaging in and abstaining from tattooing, a limited number of motives were presented to participants, and did not likely represent the attitudes of all adolescents.

Fifth, while the method of data collection was useful in many ways, it was also limiting to the study. Because self-report questionnaires were used, it was very difficult to determine how truthful students were in answering the survey items. This is especially an issue when participants, like those in the current study, are asked sensitive questions in a classroom setting. Surveys conducted in a more private setting could yield more reliable results in terms of participant honesty.

\section{Future Research}

Current and prior research on adolescent tattooing and high-risk behavior have uncovered many possible directions for future research that stem from the limitations of research studies as well as from the inconsistent findings among them. In terms of tattooed adolescents, further research should be conducted on socially and ethnically diverse samples. In light of the discrepant findings on gender and tattooing among several studies, additional research that addresses the prevalence of tattooing among males and females is needed. Although the relationship between tattoo motive and high-risk behavior has been examined very little, results of the current study partially supported such a relationship, emphasizing the need for more research on this topic. 
Further, the study of adolescent tattooing should be extended to include other aspects of personality and/or behavior that might also account for individual differences among the larger group of adolescent tattooees.

Future research would also benefit from examining non-tattooed adolescents more closely. For instance, further examination of adolescents' motives to abstain from tattooing could provide insight into the lifestyle, choices, and attitudes of this particular group. Non-tattooed participants in the current study were selected to be part of the sample because they had no intentions of becoming tattooed in the future. This step was taken to ensure the use of distinct groups, based on attitude toward tattoos. Future research could benefit, however, by looking at non-tattooed individuals who $d o$ intend to become tattooed in the future. Examination of these individuals could highlight the ways in which they are similar to, or different from, their tattooed and other non-tattooed peers.

\section{Conclusion}

The current study confirmed several outcomes of related research on adolescent tattooing and high-risk behavior, including the finding that tattooing and high-risk behavior among adolescents are related. Thus, the presence of a tattoo on an individual could indicate that he or she is also engaging in other behaviors deemed risky. Caution should be used, however, in making this assumption. While research supports an association between body modification and high-risk behavior, other internal and environmental factors affecting the adolescent should be taken into consideration in order to gain an understanding of the adolescent's overall lifestyle.

A notable extension of the research has also been made. The main objective 
of the present study was met, as adolescents' motives for becoming tattooed were examined, classified, and found to be related in some ways to high-risk behavior. The present study has identified tentative motive classifications as well as uncovered some relationships between motives and high-risk behaviors among adolescent tattooees. Current findings have demonstrated the need for further research on adolescent tattooees as a diverse group of individuals. Few, if any, other research studies have empirically tested motives to become tattooed. The present study has successfully done so, adding support to theory with scientific research, as well as opening the door to an important topic in the study of adolescent tattooees. 


\section{References}

Adler, P.A., \& Adler, P. (1978). Tinydopers: A case study of deviant socialization. Symbolic Interaction, 1, 90-105.

Armstrong, M.L., \& Pace Murphy, K. (1999). Tattooing: Another adolescent risk behavior warranting health education. In M.L. Damhorst, K.A. Miller, \& S.O. Michelman (Eds.), The meanings of dress (pp. 46-50). New York: Fairchild.

Armstrong, M.L., Roberts, A.E., Owen, D.C., \& Koch, J.R. (2004). Toward building a composite of college student influences with body art. Issues in Comprehensive Pediatric Nursing, 27, 277-295.

Arnett, J. (1995). The young and the reckless: Adolescent reckless behavior. Current Directions in Psychological Science, 4, 67-71.

Arnett, J.J. (1996). Sensation seeking, aggressiveness, and adolescent reckless behavior. Personality \& Individual Differences, 20, 693-702.

Arnett, J.J. (1998). Risk behavior and family role transitions during the twenties. Journal of Youth and Adolescence, 27, 301-320.

Atkinson, M. (2003). Tattooed: The sociogenesis of a body art. Toronto, Ontario, Canada: University of Toronto Press.

Becker, H.S. (1978). Becoming a marihuana user. In J.G. Manis \& B.N. Meltzer (Eds.), Symbolic interaction (pp. 337-344). Boston: Allyn \& Bacon.

Bianchi, R.S. (1988). Tattoo in ancient Egypt. In A. Rubin (Ed.), Marks of civilization: Artistic transformations of the human body (pp. 21-28). Los Angeles: Museum of Cultural History. 
Biglan, A., \& Cody, C. (2003). Preventing multiple problem behaviors in adolescence. In D. Romer (Ed.), Reducing adolescent risk: Toward an integrated approach (pp. 125-131). Thousand Oaks, CA: Sage.

Blumer, H. (1970). Sociological implications of the thought of George Herbert Mead. In G.P. Stone \& H.A. Farberman (Eds.), Social psychology through symbolic interaction (pp. 282-293). Waltham, MA: Xerox College.

Brener, N.D., Kann, L., McManus, T., Kinchen, S.A., Sundberg, E.C., \& Ross, J.G. (2002). Reliability of the 1999 youth risk behavior survey questionnaire. Journal of Adolescent Health, 31, 336-342.

Brooks, T.L., Woods, E.R., Knight, J.R., \& Shrier, L.A. (2003). Body modification and substance use in adolescents: Is there a link?. Journal of Adolescent Health, 32, 44-49.

Byrnes, J.P. (2003). Changing views on the nature and prevention of adolescent risk taking. In D. Romer (Ed.), Reducing adolescent risk: Toward an integrated approach (pp. 11-17). Thousand Oaks, CA: Sage.

Carroll, S.T., Riffenburgh, R.H., Roberts, T.A., \& Myhre, E.B. (2002). Tattoos and body piercings as indicators of adolescent risk-taking behaviors. Pediatrics, 109, 1021-1027.

Centers for Disease Control and Prevention. (2006). Youth risk behavior surveillance - United States, 2005 [Electronic version]. Morbidity and Mortality Weekly Report, 55, 1-112.

DeMello, M. (1995). "Not just for bikers anymore": Popular representations of American tattooing. Journal of Popular Culture, 29, 37-52. 
Deschesnes, M., Finès, P., \& Demers, S. (2006). Are tattooing and body piercing indicators of risk-taking behaviours among high school students? Journal of Adolescence, 29, 379-393.

DiClemente, R.J., Wingood, G.M., \& Crosby, R.A. (2003). A contextual perspective for understanding and preventing STD/HIV among adolescents. In D. Romer (Ed.), Reducing adolescent risk: Toward an integrated approach (pp. 366373). Thousand Oaks, CA: Sage.

Donohew, L., Palmgreen, P., Zimmerman, R., Harrington, N., \& Lane, D. (2003). Health risk takers and prevention. In D. Romer (Ed.), Reducing adolescent risk: Toward an integrated approach (pp. 165-170). Thousand Oaks, CA: Sage.

Donovan, J.E., \& Jessor, R. (1985). Structure of problem behavior in adolescence and young adulthood. Journal of Consulting and Clinical Psychology, 53, 890-904.

Drewal, H.J. (1988). Beauty and being: Aesthetics and ontology in Yoruba body art. In A. Rubin (Ed.), Marks of civilization: Artistic transformations of the human body (pp. 83-96). Los Angeles: Museum of Cultural History.

Drews, D.R., Allison, C.K., \& Probst, J.R. (2000). Behavioral and self-concept differences in tattooed and nontattooed college students. Psychological Reports, 86, 475-481.

Erikson, K.T. (1970). The sociology of deviance. In G.P. Stone \& H.A. Farberman (Eds.), Social psychology through symbolic interaction (pp. 709-716). Waltham, MA: Xerox College. 
Faules, D.F., \& Alexander, D.C. (1978). Communication and social behavior: A symbolic interaction perspective. Reading, MA: Addison-Wesley.

Field, A. (2005). Discovering statistics using SPSS ( $2^{\text {nd }}$ ed.). London: Sage.

Goffman, E. (1978). The presentation of self to others. In J.G. Manis \& B.N. Meltzer (Eds.), Symbolic interaction (pp. 171-178). Boston: Allyn \& Bacon.

Greif, J., Hewitt, W., \& Armstrong, M.L. (1999). Tattooing and body piercing. Clinical Nursing Research, 8, 368-385.

Gritton, J. (1988). Labrets and tattooing in Native Alaska. In A. Rubin (Ed.), Marks of civilization: Artistic transformations of the human body (pp. 181-190). Los Angeles: Museum of Cultural History.

Grumet, G.W. (1983). Psychodynamic implications of tattoos. American Journal of Orthopsychiatry, 53, 482-492.

Houghton, S.J., Durkin, K., Parry, E., Turbett, Y., \& Odgers, P. (1996). Amateur tattooing practices and beliefs among high school adolescents. Journal of Adolescent Health, 19, 420-425.

Irwin, K. (2001). Legitimating the first tattoo: Moral passage through informal interaction. Symbolic Interaction, 24, 49-73.

Johnson, K.K.P., \& Lennon, S.J. (1999). Introduction: Appearance and social power. In K.K.P. Johnson \& S.J. Lennon (Eds.), Appearance and power (pp. 1-10). Oxford: Berg.

Kaiser, S.B. (1997). Toward a contextual perspective. In S.B. Kaiser (Ed.), The social psychology of clothing (2nd ed., pp. 29-63). New York: Fairchild. 
Katz, J. (1988). Seductions of crime: Moral and sensual attractions in doing evil. New York: Basic Books.

Koch, J.R., Roberts, A.E., Armstrong, M.L., \& Owen, D.C. (2005). College students, tattoos, and sexual activity. Psychological Reports, 97, 887-890.

Lapsley, D.K. (2003). The two faces of adolescent invulnerability. In D. Romer (Ed.), Reducing adolescent risk: Toward an integrated approach (pp. 25-31). Thousand Oaks, CA: Sage.

Lerman, C., Patterson, F., \& Shields, A. (2003). Genetic basis of substance use and dependence: Implications for prevention in high-risk youth. In D. Romer (Ed.), Reducing adolescent risk: Toward an integrated approach (pp. 149-164). Thousand Oaks, CA: Sage.

Manis, J.G., \& Meltzer, B.N. (1978a). Intellectual antecedents and basic propositions of symbolic interactionism. In J.G. Manis \& B.N. Meltzer (Eds.), Symbolic interaction (pp. 1-9). Boston: Allyn \& Bacon.

Manis, J.G., \& Meltzer, B.N. (1978b). Society. In J.G. Manis \& B.N. Meltzer (Eds.), Symbolic interaction (pp. 11-14). Boston: Allyn \& Bacon.

McCallum, D. (1988). Historical and cultural dimensions of the tattoo in Japan. In A. Rubin (Ed.), Marks of civilization: Artistic transformations of the human body (pp. 109-134). Los Angeles: Museum of Cultural History.

Mead, G.H. (1934/1964). Mind. In Anselm Strauss (Ed.), George Herbert Mead: On social psychology (pp. 115-196). Chicago: University of Chicago Press. (Reprinted from Mind, self, and society, pp. 1-134, by C.W. Morris, Ed., 1934, Chicago: University of Chicago Press) 
Mead, G.H. (1959/1964). Reality of perspectives. In Anselm Strauss (Ed.), George Herbert Mead: On social psychology (pp. 342-354). Chicago: University of Chicago Press. (Reprinted from Philosophy of the present, pp. 161-175, by A.E. Murphy, Ed., 1959, LaSalle, IL: Open Court Publishing)

Mead, G.H. (1970). Self as social object. In G.P. Stone \& H.A. Farberman (Eds.), Social psychology through symbolic interaction (pp. 383-386). Waltham, MA: Xerox College.

Meltzer, B.N., Petras, J.W., \& Reynolds, L.T. (1978). Varieties of symbolic interactionism. In J.G. Manis \& B.N. Meltzer (Eds.), Symbolic interaction (pp. 41-58). Boston: Allyn \& Bacon.

Miller, K.A. (1999). The body in cultural context. In M.L. Damhorst, K.A. Miller, \& S.O. Michelman (Eds.), The meanings of dress (pp. 12-24). New York: Fairchild.

O'Neal, G.S. (1999). The power of style: On rejection of the accepted. In K.K.P. Johnson \& S.J. Lennon (Eds.), Appearance and power (pp. 127-139). Oxford: Berg.

Phelan, M.P., \& Hunt, S.A. (1998). Prison gang members' tattoos as identity work: The visual communication of moral careers. Symbolic Interaction, 21, 277298.

Polhemus, T. (1994/1999). Tribal styles. In M.L. Damhorst, K.A. Miller, \& S.O. Michelman (Eds.), The meanings of dress (pp. 451-454). New York: Fairchild. (Reprinted from Streetstyle, by T. Polhemus, 1994, New York: Thames \& Hudson) 
Roberts, T.A., \& Ryan, S.A. (2002). Tattooing and high-risk behavior in adolescents. Pediatrics, 110, 1058-1063.

Rubin, A. (1988a). General introduction. In A. Rubin (Ed.), Marks of civilization: Artistic transformations of the human body (pp. 13-17). Los Angeles: Museum of Cultural History.

Rubin, A. (1988b). The tattoo renaissance. In A. Rubin (Ed.), Marks of civilization: Artistic transformations of the human body (pp. 233-262). Los Angeles: Museum of Cultural History.

Sanders, C.R. (1988). Marks of mischief: Becoming and being tattooed. Journal of Contemporary Ethnography, 16, 395-432.

Sanders, C.R. (1989). Customizing the body: The art and culture of tattooing. Philadelphia: Temple University Press.

Sanders, C. (1991/1999). Memorial decoration: Women, tattooing, and the meaning of body alteration. In M.L. Damhorst, K.A. Miller, \& S.O. Michelman (Eds.), The meanings of dress (pp. 140-146). New York: Fairchild. (Reprinted from Michigan Quarterly Review, by W.B. Saunders, Ed., 1991)

Stanton, B.F., \& Burns, J. (2003). Sustaining and broadening intervention effect: Social norms, core values, and parents. In D. Romer (Ed.), Reducing adolescent risk: Toward an integrated approach (pp. 193-200). Thousand Oaks, CA: Sage.

Steinberg, L. (2003). Is decision making the right framework for research on adolescent risk taking?. In D. Romer (Ed.), Reducing adolescent risk: Toward an integrated approach (pp. 18-24). Thousand Oaks, CA: Sage. 
Stone, G.P. (1970). Appearance and the self. In G.P. Stone \& H.A. Farberman (Eds.), Social psychology through symbolic interaction (pp. 394-414). Waltham, MA: Xerox College.

Stone, G.P., \& Farberman, H.A. (1970a). The definition of the situation. In G.P. Stone \& H.A. Farberman (Eds.), Social psychology through symbolic interaction (pp. 147-153). Waltham, MA: Xerox College.

Stone, G.P., \& Farberman, H.A. (1970b). Symbolic interaction: Perspective and directions. In G.P. Stone \& H.A. Farberman (Eds.), Social psychology through symbolic interaction (pp. 11-20). Waltham, MA: Xerox College.

Stryker, S. (1978). Symbolic interaction as an approach to family research. In J.G. Manis \& B.N. Meltzer (Eds.), Symbolic interaction (pp. 323-331). Boston: Allyn \& Bacon.

Szostak-Pierce, S. (1999). Even further: The power of subcultural style in techno culture. In K.K.P. Johnson \& S.J. Lennon (Eds.), Appearance and power (pp. 141-151). Oxford: Berg.

Tabachnick, B.G., \& Fidell, L.S. (2001). Using multivariate statistics $\left(4^{\text {th }}\right.$ ed.). Boston: Allyn \& Bacon.

Teilhet-Fisk, J. (1988). The spiritual significance of Newar tattoos. In A. Rubin (Ed.), Marks of civilization: Artistic transformations of the human body (pp. 135139). Los Angeles: Museum of Cultural History.

Warr, M. (1993). Age, peers, and delinquency. Criminology, 31, 17-40. 


\title{
APPENDIX A
}

\section{PILOT QUESTIONNAIRE}

\author{
Experience with Tattoos
}

The following questions ask you to describe your personal experience with tattoos. If you choose not to participate in the survey, you may return this questionnaire to the researcher at this time. If you choose not to complete the survey, it will not have an effect on your grade in this class. Your answers to the following questions will remain completely anonymous. It should only take about 10 minutes to answer the following questions.

1. Age: (In years)

2. Gender: (Please circle one) Female Male

3. Class Rank: (Please circle one) Fr. So. Jr. Sr. Gr.

4. Do you have any tattoos? (Please circle one) Yes No If $\boldsymbol{y} \boldsymbol{e s}$, answer questions 7-11. If no, answer questions 5 and 6.

5. Are there any particular reasons why you don't have a tattoo? List as many reasons as you can think of.

6. Do you think you will get a tattoo in the future? (please check one):

Yes

No

Maybe I don't know 
7. How many tattoos do you have?

(Count each separate, distinct design as one tattoo.)

8. Please list as many reasons that you can think of to explain why you became tattooed (for example, to be unique or to celebrate a special event in your life).

9. Now that you have a tattoo, has it been a positive or negative experience for you? Why or why not? 
10. Do you regret becoming tattooed? Why or why not?

11. For each tattoo, please indicate the following: (If you have received more than 1 tattoo, please use the following page to provide information on the first 3 tattoos you received.)

\begin{tabular}{|c|c|}
\hline Tattoo \#1 & \\
\hline Age (in years) at which you received this tattoo: & $\begin{array}{l}\text { Where on your body is your tattoo located? } \\
\text { (please check all that apply) } \\
\text { Head }\end{array}$ \\
\hline $\begin{array}{l}\text { Was this tattoo applied by an amateur (e.g. a } \\
\text { friend, yourself, etc.) or by a professional } \\
\text { tattooist? } \\
\text { Amateur } \\
\text { Professional }\end{array}$ & $\begin{array}{l}\text { Face } \\
\text { Neck } \\
\text { Shoulder } \\
\text { Upper arm (above elbow, below shoulder) } \\
\text { Lower arm (below elbow, above wrist) } \\
\text { Hand or wrist }\end{array}$ \\
\hline $\begin{array}{l}\text { What is the size of your tattoo? } \\
\text { Small (baseball-size or smaller) } \\
\text { Medium (about the size of an arm band) } \\
\text { Large (about the size of a half sleeve) } \\
\text { Extra large (larger than those listed above, } \\
\text { including full sleeves and images spanning an } \\
\text { entire body area) } \\
\text { Other (please specify) }\end{array}$ & $\begin{array}{ll} & \text { Chest } \\
\text { Stomach } \\
\text { Sides of torso } \\
\text { Upper back } \\
\text { Lower back } \\
\text { Buttocks } \\
\text { Hip or waist } \\
\text { Upper leg (above knee, below hip) } \\
\text { Lower leg (below knee, above ankle) } \\
\text { Ankle } \\
\text { Foot } \\
\text { Genitals } \\
\text { Other (please specify) }\end{array}$ \\
\hline
\end{tabular}




\begin{tabular}{|c|c|}
\hline Tattoo \#2 & \\
\hline Age (in years) at which you received this tattoo: & $\begin{array}{l}\text { Where on your body is your tattoo located? } \\
\text { (please check all that apply) } \\
\text { Head }\end{array}$ \\
\hline $\begin{array}{l}\text { Was this tattoo applied by an amateur (e.g. a } \\
\text { friend, yourself, etc.) or by a professional } \\
\text { tattooist? } \\
\text { Amateur } \\
\text { Professional }\end{array}$ & $\begin{array}{l}\text { Face } \\
\text { Neck } \\
\text { Shoulder } \\
\text { Upper arm (above elbow, below shoulder) } \\
\text { Lower arm (below elbow, above wrist) } \\
\text { Hand or wrist }\end{array}$ \\
\hline $\begin{array}{l}\text { What is the size of your tattoo? } \\
\text { Small (baseball-size or smaller) } \\
\text { Medium (about the size of an arm band) } \\
\text { Large (about the size of a half sleeve) } \\
\text { Extra large (larger than those listed above, } \\
\text { including full sleeves and images spanning an } \\
\text { entire body area) } \\
\text { Other (please specify) }\end{array}$ & $\begin{array}{l}\text { Chest } \\
\text { Stomach } \\
\text { Sides of torso } \\
\text { Upper back } \\
\text { Lower back } \\
\text { Buttocks } \\
\text { Hip or waist } \\
\text { Upper leg (above knee, below hip) } \\
\text { Lower leg (below knee, above ankle) } \\
\text { Ankle } \\
\text { Foot } \\
\text { Genitals } \\
\text { Other (please specify) }\end{array}$ \\
\hline
\end{tabular}

\begin{tabular}{|c|c|}
\hline Tattoo \#3 & \\
\hline Age (in years) at which you received this tattoo: & $\begin{array}{l}\text { Where on your body is your tattoo located? } \\
\text { (please check all that apply) } \\
\text { Head } \\
\text { Face } \\
\text { Neck } \\
\text { Shoulder } \\
\text { Upper arm (above elbow, below shoulder) } \\
\text { Lower arm (below elbow, above wrist) } \\
\text { Hand or wrist } \\
\text { Chest } \\
\text { Stomach } \\
\text { Sides of torso } \\
\text { Upper back } \\
\text { Lower back } \\
\text { Buttocks } \\
\text { Hip or waist } \\
\text { Upper leg (above knee, below hip) } \\
\text { Lower leg (below knee, above ankle) } \\
\text { Ankle } \\
\text { Foot } \\
\text { Genitals } \\
\text { Other (please specify) }\end{array}$ \\
\hline
\end{tabular}




\section{APPENDIX B}

\section{PILOT STUDY COVER LETTER TO PARTICIPANTS}

October 13, 2006

Dear Student:

Your participation is requested in completing the attached questionnaire for a research study that will examine adolescent tattooing behavior. The following research study will be conducted for partial fulfillment of the requirements for a master's thesis in the Department of Technology, Learning and Culture in the College of Human Resources and Education at West Virginia University. You are being asked to complete the attached questionnaire, which should take about 10 minutes to complete. The information obtained from the current study will be used to develop a questionnaire for a future research study.

In order to participate in this study, you must be at least 18 years of age. Participants will remain anonymous, and will not be asked to provide a name, university identification number, or any other identifier. In addition, participants' responses to all questions will remain confidential. Those individuals participating in the study are not required to answer every question, and may withdraw from the study at any time. Participants' grade, class standing, or athletic team status will not be affected by participation, refusal, or withdrawal from the present study. Finally, participation in the following study is completely voluntary. Thank you for your time and consideration.

Sincerely,

Tiffany L. Stickel

Graduate Student

Technology, Learning and Culture

(304) 293-3545

tstickel@mix.wvu.edu

West Virginia University Office of Research Compliance (304)293-7073

Carruth Center for Counseling and Psychological Services

$3^{\text {rd }}$ Floor, Student Services Center

(304)293-4431 


\section{APPENDIX C \\ PILOT QUESTIONNAIRE RESULTS: ITEMS 5 AND 8-10}

Table C1

Pilot Item 5 Responses and Corresponding Research Questionnaire Items

\begin{tabular}{|c|c|c|}
\hline $\begin{array}{l}\text { Research } \\
\text { Questionnaire } \\
\text { Item }\end{array}$ & $\begin{array}{l}\text { 5. Are there any particular reasons why you don't } \\
\text { have a tattoo? }\end{array}$ & $\begin{array}{l}\text { Number of } \\
\text { Respondents }\end{array}$ \\
\hline $6 a$ & $\begin{array}{l}\text { My friends/family do not like tattoos. } \\
\text { My parents don't like it. } \\
\text { My parents will stop giving me money. } \\
\text { My family is against it. } \\
\text { My parents won't allow it. } \\
\text { I'd worry about hiding it from my family. }\end{array}$ & $\begin{array}{l}17 \\
3 \\
3 \\
1 \\
1\end{array}$ \\
\hline $6 \mathbf{b}$ & $\begin{array}{l}\text { I do not want something that permanent on my } \\
\text { body. } \\
\text { I don't want something that permanent. } \\
\text { I can't think of anything that I would want on my } \\
\text { body for the rest of my life. }\end{array}$ & $\begin{array}{l}21 \\
12\end{array}$ \\
\hline 6c & $\begin{array}{l}\text { I do not have the desire to get a tattoo. } \\
\text { I don't have the desire to get one. } \\
\text { It's not a top priority for me. } \\
\text { It's unnecessary. }\end{array}$ & $\begin{array}{l}15 \\
1 \\
1\end{array}$ \\
\hline 6d & $\begin{array}{l}\text { I might not like the tattoo when I get older. } \\
\text { I might not like it later. } \\
\text { I don't want it to look bad later. } \\
\text { I might regret it later. } \\
\text { It will wrinkle. }\end{array}$ & $\begin{array}{l}21 \\
10 \\
4 \\
1\end{array}$ \\
\hline $6 e$ & $\begin{array}{l}\text { Tattoos are too expensive. } \\
\text { They are too expensive. }\end{array}$ & 14 \\
\hline 6f & $\begin{array}{l}\text { I don't like tattoos. } \\
\text { They look trashy. } \\
\text { I don't like the way they look. } \\
\text { I don't like them. } \\
\text { They are ugly. } \\
\text { It doesn't suit my personality. } \\
\text { It's not my style. } \\
\text { They are stupid. }\end{array}$ & $\begin{array}{l}8 \\
4 \\
2 \\
2 \\
2 \\
1 \\
1\end{array}$ \\
\hline $6 g$ & $\begin{array}{l}\text { I actually do want one, but I haven't had the } \\
\text { money or opportunity to get one yet. } \\
\text { I don't have enough money to get one. } \\
\text { I haven't had the time to get one. } \\
\text { I haven't found the right artist. }\end{array}$ & $\begin{array}{l}9 \\
4 \\
1\end{array}$ \\
\hline
\end{tabular}




\begin{tabular}{|c|c|c|}
\hline $\begin{array}{l}\text { Research } \\
\text { Questionnaire } \\
\text { Item }\end{array}$ & $\begin{array}{l}\text { 5. Are there any particular reasons why you don't } \\
\text { have a tattoo? }\end{array}$ & $\begin{array}{l}\text { Number of } \\
\text { Respondents }\end{array}$ \\
\hline $6 h$ & $\begin{array}{l}\text { I actually do want one, but I don't know what I } \\
\text { would like to get/where I would like to place it on } \\
\text { my body. } \\
\text { I don't know where I would get it (on my body). } \\
\text { I don't know what I want. } \\
\text { I haven't found one that I like. } \\
\text { I need to think of something meaningful first. }\end{array}$ & $\begin{array}{c}11 \\
10 \\
5 \\
4\end{array}$ \\
\hline $6 \mathbf{i}$ & $\begin{array}{l}\text { It is against my beliefs. } \\
\text { Because of my religion. }\end{array}$ & 6 \\
\hline 6j & $\begin{array}{l}\text { I am afraid of the pain/needles. } \\
\text { I'm scared of the pain. } \\
\text { I have a fear of needles. }\end{array}$ & $\begin{array}{c}18 \\
8\end{array}$ \\
\hline 6k & $\begin{array}{l}\text { My job does not allow tattoos. } \\
\text { Because of my job. } \\
\text { They don't look professional. }\end{array}$ & $\begin{array}{l}5 \\
2 \\
\end{array}$ \\
\hline Not Used & $\begin{array}{l}\text { These responses were not used to devise questions. } \\
\text { No reason. } \\
\text { I'm indecisive. } \\
\text { I'm afraid of getting a disease or infection. } \\
\text { I don't feel comfortable getting tattooed by just } \\
\text { anyone. } \\
\text { The issue has never come up. } \\
\text { I'm too scared to go into the tattoo parlor. } \\
\text { The artist might do a bad job. } \\
\text { I don't want to just get one for no reason. } \\
\text { I don't want one right now. } \\
\text { It is there for everyone to see. } \\
\text { I want to set an example for my children. } \\
\text { I've never really thought about it. } \\
\text { I can't sit still long enough to get one. } \\
\text { I'm not confident enough in my body to get one. } \\
\text { I don't want to destroy my body. } \\
\text { If you have too many, it looks bad. } \\
\text { They have no cultural significance to me. } \\
\text { Tattoos connote sexual promiscuity. } \\
\text { They're just a fad. }\end{array}$ & $\begin{array}{l}2 \\
1 \\
1 \\
1 \\
1 \\
1 \\
1 \\
1 \\
1 \\
1 \\
1 \\
1 \\
1 \\
1 \\
1\end{array}$ \\
\hline
\end{tabular}

Note. The first column indicates the choice under which each reason (in the second column) is represented. The third column shows the number of respondents that cited each particular reason for not becoming tattooed. 
Table C2

Pilot Items 8-10 Responses and Corresponding Research Questionnaire Items

\begin{tabular}{|c|c|c|c|c|c|c|}
\hline $\begin{array}{c}\text { Research } \\
\text { Questionnaire } \\
\text { Item }\end{array}$ & $\begin{array}{l}\text { 8. Please list as many reasons } \\
\text { that } \\
\text { you can think of to explain } \\
\text { why you became tattooed. }\end{array}$ & $\begin{array}{l}\text { Number of } \\
\text { Respondents }\end{array}$ & \multicolumn{2}{|c|}{$\begin{array}{l}\text { 9. Positive or } \\
\text { Negative } \\
\text { Experience }\end{array}$} & \multicolumn{2}{|c|}{$\begin{array}{l}\text { 10. Did you } \\
\text { regret it? }\end{array}$} \\
\hline & & & Pos. & Neg. & Yes & No \\
\hline $\mathbf{4 a}$ & $\begin{array}{l}\text { My friends or someone } \\
\text { I know wanted me to get one. } \\
\text { My friends and I wanted } \\
\text { to get the same one together. }\end{array}$ & 2 & 2 & & & 2 \\
\hline 4b & $\begin{array}{l}\text { To express myself/be unique. } \\
\text { To express myself. } \\
\text { To be unique. }\end{array}$ & $\begin{array}{l}3 \\
2 \\
\end{array}$ & $\begin{array}{l}3 \\
2 \\
\end{array}$ & 1 & 1 & $\begin{array}{l}2 \\
2\end{array}$ \\
\hline $4 c$ & $\begin{array}{l}\text { I like how tattoos look. } \\
\text { I liked the design. } \\
\text { To show my appreciation for } \\
\text { art. }\end{array}$ & $\begin{array}{l}2 \\
1\end{array}$ & $\begin{array}{l}2 \\
1\end{array}$ & 1 & & $\begin{array}{l}2 \\
1\end{array}$ \\
\hline 4d & $\begin{array}{l}\text { To symbolize/remember } \\
\text { an important event or person. } \\
\text { To symbolize part of my life. } \\
\text { As a memorial for someone. } \\
\text { To remember part of my life. } \\
\text { To remember my mother's } \\
\text { struggle with cancer. } \\
\text { To celebrate my mother's } \\
\text { survival } \\
\text { of cancer. } \\
\text { To show off my body after I } \\
\text { lost } \\
\text { weight. } \\
\text { To remember special events. } \\
\text { To remember someone. } \\
\text { Symbolize a new part of my } \\
\text { life. } \\
\text { To remind me of my friends. }\end{array}$ & $\begin{array}{l}4 \\
4 \\
1 \\
1 \\
1\end{array}$ & $\begin{array}{l}4 \\
4 \\
1 \\
1\end{array}$ & 1 & & $\begin{array}{l}1 \\
1 \\
1 \\
1\end{array}$ \\
\hline $4 e$ & $\begin{array}{l}\text { I wanted something that was } \\
\text { special/meaningful to me. } \\
\text { I wanted one that was } \\
\text { meaningful/ } \\
\text { special to me. } \\
\text { To show pride in my name. } \\
\text { It has meaning. }\end{array}$ & $\begin{array}{l}3 \\
1\end{array}$ & $\begin{array}{l}2 \\
1\end{array}$ & 1 & 1 & $\begin{array}{l}2 \\
1\end{array}$ \\
\hline $\mathbf{4 f}$ & $\begin{array}{l}\text { They are cool/trendy. } \\
\text { I think they are cool. } \\
\text { Just for fun. } \\
\text { For the experience. } \\
\text { I'm fascinated by tattoos. } \\
\text { They are trendy. }\end{array}$ & $\begin{array}{l}3 \\
1 \\
1 \\
1 \\
1\end{array}$ & $\begin{array}{l}1 \\
1\end{array}$ & 1 & $\begin{array}{l}1 \\
1\end{array}$ & $\begin{array}{l}1 \\
1\end{array}$ \\
\hline
\end{tabular}




\begin{tabular}{|c|c|c|c|c|c|c|}
\hline \multirow[t]{2}{*}{$\begin{array}{l}\text { Research } \\
\text { Questionnaire } \\
\text { Item }\end{array}$} & \multirow[t]{2}{*}{$\begin{array}{l}\text { 8. Please list as many reasons that } \\
\text { you can think of to explain why } \\
\text { you became tattooed. }\end{array}$} & \multirow[t]{2}{*}{$\begin{array}{l}\text { Number of } \\
\text { Respondents }\end{array}$} & \multicolumn{2}{|c|}{$\begin{array}{l}\text { 9. Positive or } \\
\text { Negative } \\
\text { Experience }\end{array}$} & \multicolumn{2}{|c|}{$\begin{array}{l}\text { 10. Did you } \\
\text { regret it? }\end{array}$} \\
\hline & & & Pos. & Neg. & Yes & No \\
\hline $4 g$ & $\begin{array}{l}\text { To show my parents that } \\
\text { I have control over my own } \\
\text { life. } \\
\text { To be rebellious. }\end{array}$ & 1 & 1 & & & 1 \\
\hline $4 h$ & $\begin{array}{l}\text { To symbolize what I believe in. } \\
\text { It is a lifelong remembrance of } \\
\text { things that are important to me. } \\
\text { Religious reasons. } \\
\text { Reminder to be myself/who I am. } \\
\text { Symbolize something I believe in. }\end{array}$ & $\begin{array}{l}2 \\
1 \\
1 \\
1\end{array}$ & $\begin{array}{l}2 \\
1 \\
1 \\
1\end{array}$ & & & $\begin{array}{l}1 \\
1 \\
1\end{array}$ \\
\hline Not Used & $\begin{array}{l}\text { These responses were not used } \\
\text { to devise questions. } \\
\text { I wanted one. } \\
\text { To celebrate my birthday. } \\
\text { I wanted one that was unique. } \\
\text { To be ordinary. } \\
\text { To have something to share with } \\
\text { my best friend (who designed my } \\
\text { tattoo). } \\
\text { It's a way to deal with stress. } \\
\text { For an endorphin "rush." } \\
\text { My tattoos made me who I am } \\
\text { today. } \\
\text { To show pride in sports teams that } \\
\text { I support. } \\
\text { It was actually a mistake. } \\
\text { To symbolize my different } \\
\text { personalities. } \\
\text { To celebrate my heritage. } \\
\text { Because I can cover it if I want to. } \\
\text { I like the idea of the permanency. } \\
\text { It was a bonding experience (with } \\
\text { the person that went with me). }\end{array}$ & $\begin{array}{l}1 \\
1 \\
1 \\
1 \\
1 \\
1 \\
1 \\
1 \\
1 \\
1\end{array}$ & $\begin{array}{l}7 \\
3 \\
2 \\
1 \\
1\end{array}$ & $\begin{array}{l}1 \\
1\end{array}$ & $\begin{array}{l}1 \\
1\end{array}$ & $\begin{array}{l}8 \\
3 \\
2 \\
1 \\
1\end{array}$ \\
\hline
\end{tabular}

Note. The first column indicates the choice under which each reason (in the second column) is represented. The third column shows the number of respondents that cited each particular reason for becoming tattooed. Information obtained from items 9 and 10 of the pilot questionnaire were included and are reflected in the fourth and fifth columns of the table. The fourth column includes the number of participants who cited positive or negative attitudes associated with each response. The fifth column includes the number of participants who regretted and did not regret becoming tattooed, in association with each response. The choices for numbers 9 and 10 of the pilot questionnaire were not mutually exclusive; participants sometimes reflected positive and negative attitudes and expressed regret and non-regret. 


\section{APPENDIX D}

\section{RESEARCH QUESTIONNAIRE}

Tattooing, Behavior, and Identity

The following questions ask you to describe your personal experience with tattoos, your engagement in certain behaviors, as well as your feelings about your personal identity. Participation in this survey is completely voluntary. If you do choose to complete the survey, you are not required to answer every question. Your answers to the following questions will remain completely anonymous. It should only take about 15 minutes to answer the following questions.

1 Do you have any tattoos?
a Yes
b No

2 How many tattoos do you have? (please enter $\mathbf{0}$ if you do not have any tattoos)

3 How many times have you gone somewhere to become tattooed?

4 Why did you choose to become tattooed?

For each item listed below, please rate how important each factor was in your decision to become tattooed. Please circle one response for each item.

a My friends or someone I know wanted me to get a tattoo.

b I wanted to express myself/be unique.

c I like how tattoos look.

d I wanted to symbolize/remember an important event or person.

e I wanted something that was special/meaningful to me.

f I think tattoos are cool/trendy.

g I wanted to show my parents that I have control over my own life.

h I wanted to symbolize what I believe in.

i Other (Please specify.)
Not at all

Important

Somewhat

Unimportant

Neutral

Somewhat
Important

Very Important

2

3

4

5

5

5

5

5

5

5

5

5 
5 Do you regret becoming tattooed?
a Yes
b No

6 Answer this question if you have $\boldsymbol{n o}$ tattoos. (Those with tattoos please skip this question and continue with number 8.)

Why did you choose not to become tattooed?

\begin{tabular}{|c|c|c|c|c|c|c|}
\hline \multicolumn{2}{|c|}{$\begin{array}{l}\text { For each item listed below, please rate how } \\
\text { important each factor was in your decision } \\
\text { to not become tattooed. Please circle one } \\
\text { response for each item. }\end{array}$} & $\begin{array}{l}\text { Not at all } \\
\text { Important }\end{array}$ & $\begin{array}{l}\text { Somewhat } \\
\text { Un- } \\
\text { important }\end{array}$ & Neutral & $\begin{array}{l}\text { Somewhat } \\
\text { Important }\end{array}$ & $\begin{array}{c}\text { Very } \\
\text { Important }\end{array}$ \\
\hline a & My parents/family do not like tattoos. & 1 & 2 & 3 & 4 & 5 \\
\hline $\mathrm{b}$ & $\begin{array}{l}\text { I do not want something that } \\
\text { permanent on my body. }\end{array}$ & 1 & 2 & 3 & 4 & 5 \\
\hline $\mathrm{c}$ & I do not have the desire to get a tattoo. & 1 & 2 & 3 & 4 & 5 \\
\hline $\mathrm{d}$ & $\begin{array}{l}\text { I might not like the tattoo when I get } \\
\text { older. }\end{array}$ & 1 & 2 & 3 & 4 & 5 \\
\hline $\mathrm{e}$ & Tattoos are too expensive. & 1 & 2 & 3 & 4 & 5 \\
\hline $\mathrm{f}$ & I don't like tattoos. & 1 & 2 & 3 & 4 & 5 \\
\hline g & $\begin{array}{l}\text { I actually do want one, but I haven't } \\
\text { had the money or opportunity to get } \\
\text { one yet. }\end{array}$ & 1 & 2 & 3 & 4 & 5 \\
\hline $\mathrm{h}$ & $\begin{array}{l}\text { I actually do want one, but I don't } \\
\text { know what I would like to get/where I } \\
\text { would like to place it on my body. }\end{array}$ & 1 & 2 & 3 & 4 & 5 \\
\hline $\mathrm{i}$ & It is against my beliefs. & 1 & 2 & 3 & 4 & 5 \\
\hline $\mathrm{j}$ & I am afraid of the pain/needles. & 1 & 2 & 3 & 4 & 5 \\
\hline $\mathrm{k}$ & My job does not allow tattoos. & 1 & 2 & 3 & 4 & 5 \\
\hline 1 & Other (Please specify.) & 1 & 2 & 3 & 4 & 5 \\
\hline
\end{tabular}

7 If you do not have any tattoos, do you think you will get one in the future?

a I probably will.

b I probably will not. 


\section{Everyone please respond to the remaining items.}

8 During the past 30 days, on how many days did you smoke cigarettes? ${ }^{2}$
a 0 days
b 1 or 2 days
c 3 to 5 days
d 6 to 9 days
e 10 to 19 days
f 20 to 29 days
g All 30 days

9 During the past 30 days, on the days that you smoked, how many cigarettes did you smoke per day?

a I did not smoke cigarettes during the past 30 days

b Less than 1 cigarette per day

c 1 cigarette per day

d 2 to 5 cigarettes per day

e 6 to 10 cigarettes per day

f 11 to 20 cigarettes per day

g More than 20 cigarettes per day

10 During the past 30 days, on how many days did you have at least one drink of alcohol?
a days
b 1 or 2 days
c 3 to 5 days
d 6 to 9 days
e 10 to 19 days
f 20 to 29 days
g All 30 days

11 During the past 30 days, on how many days did you have 5 or more drinks of alcohol in a row, that is, within a couple of hours?

a days

b 1 day

c 2 days

d 3 to 5 days

e 6 to 9 days

f 10 to 19 days

g 20 or more days

\footnotetext{
${ }^{2}$ Choices in bold indicate those that are considered high-risk levels of behavior.
} 
12 During the past 30 days, how many times have you used any form of cocaine, including powder, crack, or freebase?

a 0 times

b 1 or 2 times

c 3 to 9 times

d 10 to 19 times

e 20 to 39 times

f 40 or more times

13 During your life, how many times have you sniffed glue, breathed the contents of aerosol spray cans, or inhaled any paints or sprays to get high?

a 0 times

b 1 or 2 times

c 3 to 9 times

d 10 to 19 times

e 20 to 39 times

f 40 or more times

14 During your life, how many times have you used heroin (also called smack, junk, or China White)?

a 0 times

b 1 or 2 times

c 3 to 9 times

d 10 to 19 times

e 20 to 39 times

f 40 or more times

15 During your life, how many times have you used methamphetamines (also called speed, crystal, crank, or ice)?

a 0 times

b 1 or 2 times

c 3 to 9 times

d 10 to 19 times

e 20 to 39 times

f 40 or more times

16 During your life, how many times have you used ecstasy (also called MDMA)?

a 0 times

b 1 or 2 times

c 3 to 9 times

d 10 to 19 times

e 20 to 39 times

f 40 or more times 
17 During your life, with how many people have you had sexual intercourse?

a I have never had sexual intercourse

b 1 person

c 2 people

d 3 people

e 4 people

f 5 people

g 6 or more people

18 Did you drink alcohol or use drugs before you had sexual intercourse the last time?

a I have never had sexual intercourse

b Yes

c No

19 The last time you had sexual intercourse, did you or your partner use a condom?

a I have never had sexual intercourse

b Yes

c No

20 What is your biological sex?

a Male

b Female

21 What is your age in years?

22 With which race/ethnicity do you most closely identify? (please circle all that apply)

a African-American

d Caucasian

b American Indian/Alaska Native

e Latino/a (Hispanic)

c Asian/Pacific Islander

f Other (Please specify.)

23 What is your current rank in college?
a Freshman
b Sophomore
d Senior
c Junior
e Graduate Student
$f$ Other (Please specify.)

24 What is your major in college? 
25 What are your parents' (or parental figures') highest level of education attainment?

Mother (or mother figure):

a Does not apply to me.

b Completed grade school.

c Attended some high school.

d Graduated high school.

e Attended trade/technical school.

f Graduated trade/technical school.

g Attended some college.

h Earned bachelor's degree.

i Earned master's degree.

j Earned professional degree (e.g., Ph.D., M.D., J.D.).
Father (or father figure):

a Does not apply to me.

b Completed grade school.

c Attended some high school.

d Graduated high school.

e Attended trade/technical school.

f Graduated trade/technical school.

g Attended some college.

h Earned bachelor's degree.

i Earned master's degree.

j Earned professional degree (e.g., Ph.D., M.D., J.D.)

26 What are your parents' (or parental figures') employment?

Mother (or mother figure):

Where does she work?

What kind of work does she do there?

This question does not apply to me.
Father (or father figure):

Where does he work?

What kind of work does he do there?

This question does not apply to me. 


\section{APPENDIX E \\ RESEARCH STUDY COVER LETTER TO PARTICIPANTS}

December 14, 2006

Dear Student:

Your participation is requested in completing the attached questionnaire for a research study that will examine adolescent tattooing, other behaviors, and personal identity. The following research study will be conducted for partial fulfillment of the requirements for a master's thesis in the Department of Technology, Learning and Culture in the College of Human Resources and Education at West Virginia University. You are being asked to complete the attached questionnaire, which should take about 15 minutes to complete.

In order to participate in this study, you must be at least 18 years of age. Participants will remain anonymous, and will not be asked to provide a name, university identification number, or any other identifier. In addition, participants' responses to all questions will remain confidential. Those individuals participating in the study are not required to answer every question, and may withdraw from the study at any time. Participants' grade, class standing, or athletic team status will not be affected by participation, refusal, or withdrawal from the present study. Finally, participation in the following study is completely voluntary. Thank you for your time and consideration.

Sincerely,

Tiffany L. Stickel

Graduate Student

Technology, Learning and Culture

(304) 293-3545

tstickel@mix.wvu.edu

West Virginia University Office of Research Compliance (304)293-7073

Carruth Center for Counseling and Psychological Services

$3^{\text {rd }}$ Floor, Student Services Center

(304)293-4431 


\section{Curriculum Vitae}

Tiffany Lynn Stickel

t1stickel@gmail.com

\section{Education}

M.A.

West Virginia University - Morgantown, WV

2007

Educational Psychology, with an emphasis in

Child Development and Family Studies

B.A.

West Virginia University - Morgantown, WV

2005

Exercise Physiology

Experience

May 2007 - December 2007

August 2006 - May 2007

January 2006 - May 2006

August 2005 - May 2006
West Virginia University - Morgantown, WV Part-time Instructor, Department of Technology, Learning, and Culture

On-line Course Taught: Adolescent

Development

West Virginia University - Morgantown, WV Graduate Research Assistant, Department of Family and Consumer Sciences

West Virginia University - Morgantown, WV Graduate Teaching Assistant, Native American Studies

Course Assisted: Introduction to Native American Studies

West Virginia University - Morgantown, WV Graduate Research Assistant, Department of Family and Consumer Sciences 


\title{
Referred Abstracts
}

Yoo, J., Stickel, T.L. (2007). Shopping without a list: How can we explain spontaneous shoppers?, West Virginia Association of Family and Consumer Sciences and West Virginia Extension Association of Family and Consumer Sciences Annual Meeting [abstract]. (Oral presentation)

\begin{abstract}
Submitted
Stickel, T.L. (2007). Personal care product use and peer influence among adolescents [abstract]. Submitted to the International Textile and Apparel Association

Yoo, J. Stickel, T.L. (2007) Relationship between Sociocultural Attitudes towards Appearance (SATA) and Quality of Appearance Management Behaviors among Adolescents [abstract]. Submitted to the International Textile and Apparel Association.
\end{abstract}

\section{Conferences Attended}

Professional Development

Society for Research on Adolescence

March 23-26, 2006

San Francisco, CA

\section{Community Involvement}

Volunteer, West Virginia University Children's Hospital 2004-2005

Charter member, National Exemplary Scholars in Service 2005 